\title{
An Information Processing View on Joint Vendor Performance in Multi-Sourcing: The Role of the Guardian
}

\section{Published in Journal of Management Information Systems*}

\section{Ilan Oshri ${ }^{\dagger}$}

The University of Auckland Business School, 12 Grafton Road, Auckland 1010, New Zealand

Email: ilan.oshri@auckland.ac.nz, Phone: +649923 3471

\section{Jens Dibbern ${ }^{\dagger}$}

Institute of Information Systems, University of Bern, Engehaldenstr. 8, 3012 Bern, Switzerland, Email: jens.dibbern@iwi.unibe.ch, Phone: +41316313889

\section{Julia Kotlarsky ${ }^{\dagger}$}

The University of Auckland Business School, 12 Grafton Road, Auckland 1010, New Zealand

Email: ilan.oshri@auckland.ac.nz, Phone: +64 99233305

\section{Oliver Krancher ${ }^{\dagger}$}

IT University of Copenhagen, Rued Langgaards Vej 7, 2300 Copenhagen S, Denmark, Email: olik@itu.dk, Phone: +45 72185272

${ }^{\dagger}$ All authors contributed equally.

\footnotetext{
*Cite as: Oshri, I., Dibbern, J., Kotlarsky, J. and O. Krancher (2019) “An Information Processing View on Joint Vendor Performance in Multi-Sourcing: The Role of the Guardian", Journal of Management Information Systems, 36:4, 1248-1283, DOI: 10.1080/07421222.2019.1661091
} 


\title{
An Information Processing View on Joint Vendor Performance in Multi-Sourcing: The Role of the Guardian
}

\begin{abstract}
This paper examines joint vendor performance in multi-sourcing arrangements. Using an Information Processing View, we argue that managing interdependencies between multiple vendors imposes substantial information processing (IP) requirements on clients. To achieve high joint performance, clients therefore need to possess sufficient IP capacity. We examine how three sources of IP capacity, two internal (i.e., the client's inter-vendor governance and the client's architectural knowledge) and one external (i.e., the guardian vendor), work together in realizing joint performance. Our results show that formal governance and architectural knowledge contribute to joint performance. The guardian vendor contributes to joint performance in settings where the client deploys strong governance but lacks architectural knowledge. This suggests that, contrary to common views in the literature, guardian vendors should not be understood as mediators (or single points of contact) who relieve clients from governance efforts. Instead, guardian vendors are more fruitfully understood as architects, who complement the client's governance efforts by compensating for knowledge gaps. Put simply, client firms should consider using a guardian vendor to compensate for weak architectural knowledge while still maintaining strong formal and informal governance of all vendors.
\end{abstract}

Keywords: multi-sourcing, joint performance, guardian, governance, architectural knowledge, information processing view 


\section{INTRODUCTION}

In the information systems (IS) domain, multi-sourcing is viewed as the practice of procuring interdependent information technology (IT) and business services from external vendors to achieve optimal business goals [4]. Such a definition brings to the fore the interdependencies between outsourced tasks delivered by various vendors, thus implying the need for interactions between the vendors in order to jointly deliver an overall service $[4,49]$. In assessing the success of a multi-sourcing arrangement, it is not the performance of the individual vendors that matters most, but their joint performance, i.e., the degree to which the combined services delivered by the vendors meet the client's expectations. An example of such a multi-sourcing arrangement is British Airways' (BA’s) “Know Me Programme”, which was initiated in 2013 and involves three vendors, Tata Consultancy Services (TCS), Opera Solutions, and eDialog (now Zeta Interactive) ${ }^{1}$. Together, these three vendors form a new personalized customer contact system. Although each vendor has its own responsibilities, i.e., TCS for collecting, integrating, and managing customer data, Opera Solutions for providing business analytics services, and e-Dialog for creating e-mail-based marketing services, the success of the project relies on all three services working together. Accordingly, the vendors have to manage the interdependencies between their services, which requires them to cooperate and coordinate their actions. This example resonates with Bapna et al.'s [4] claim that: "In contrast to dyadic client-vendor relationships that have been the subject of extant global sourcing research, multi-sourcing necessitates individual and collaborative efforts of multiple vendors at the back-end to come together to create a seamless, integrated service at the front end for the client” (p. 786). While facets associated with governance of dyadic relationships, such as putting in place Service

\footnotetext{
1 e-Dialog was part of GSI Commerce (which was acquired by eBay and renamed eBay Enterprise in 2013), and sold to Zeta Interactive in 2015 (http://zetaglobal.com/clients).
} 
Level Agreements (SLAs) and using various organizational controls to motivate vendors to achieve desirable results [47], are also relevant, the client firm needs to put greater effort into governing the vendor network in IT multi-sourcing [31], as well as incentivizing and monitoring both individual and joint vendor performance [4]. On this account, the use of a guardian vendor to assist the client firm in governing the vendor network [e.g., 4, 49] has been portrayed as one of the unique features of the IS multisourcing setting ${ }^{2}$.

While a few studies have examined multi-sourcing in the IS context ${ }^{3}[4,6,12,31,42$, 49], we still know little about interactions and collaboration between multiple vendors and the effects on joint performance. In this regard, research has shed light on the importance of appropriate task design (e.g., modularization) and task distribution among vendors (e.g., choosing specialized vendors while ensuring sufficient knowledge overlaps between them) [49]. However, little is known about how the client can facilitate and support vendors to achieve successful joint performance. Moreover, it is not clear how the client's support role is affected if the client assigns one of the vendors the position of guardian, i.e., the responsibility for managing the other vendors. Currently, the literature suggests that the guardian vendor acts as a mediator, thus standing between the client and the other vendors [49]. This implies that the guardian substitutes the client in facilitating and supporting coordination and cooperation activities among the vendors $[4,49]$. Alternatively, we propose that the guardian may

\footnotetext{
${ }^{2}$ It is important to note that the IS outsourcing literature has so far conceptually discussed the role of the guardian and suggested that it corresponds with the notion of a mediator. More specifically, two key studies have explored the guardian role: Bapna et al. [4] is a research commentary and largely conceptual; second, while Wiener and Saunders [49] report a case study that follows a direct rather than a guardian model, with some suggestions made regarding the guardian.

${ }^{3}$ Multi-vendor settings have been broadly studied in the supply chain literature [e.g., 1] in the context of production, logistics and procurement of physical goods (e.g., automotive and manufacturing industries), where clients use multiple suppliers to procure similar/identical physical parts. In the case of IT-enabled business processes and services, each vendor is delivering a unique yet interdependent service (as illustrated in the British Airways example in the Introduction). Thus the nature of the interdependencies and joint performance in IT multi-sourcing that are the focus of this paper is different to the interdependencies in triadic relationships between suppliers of physical parts discussed in the literature [e.g., 10].
} 
improve joint performance by providing capacities that complement those of the client. It is within these areas of interest that this paper seeks to advance our understanding of multi-sourcing settings by addressing the following questions: (i) How does the client facilitate joint vendor performance in a multi-sourcing arrangement?; and (ii) What role does the guardian vendor play in achieving joint performance?

We frame the challenge of achieving joint vendor performance (hereafter, joint performance) as an information processing (IP) issue. Hence, the challenge of achieving joint performance in a multi-sourcing arrangement is essentially one of effective IP to manage interdependencies between the vendors and between the client and the vendors, thus imposing considerable IP requirements. For instance, in the example above regarding British Airways, IP is needed to understand the functional and technical system requirements of the client (BA), and also to understand the interdependencies that exist between TCS' customer data management systems and processes, Opera Solutions' data analytics processes, and E-dialog's email platform. While such IP requirements may vary between multi-sourcing arrangements, e.g. according to the degree of modularization [44], the involvement of numerous vendors and the interdependencies between them will pose challenges to the client in achieving joint performance if the client does not ensure sufficient and relevant IP capacity. In this regard, governance (formal and informal) and architectural knowledge have repeatedly been suggested as key factors affecting IP capacities [7, 15, 33].

Consequently, we examined how clients can ensure joint performance by assuming sufficient IP capacities in multi-sourcing arrangements [15, 48], to support our claim that such IP capacities may be brought in by the client (i.e., as an internal IP capacity) or by the guardian vendor (i.e., as an external IP capacity) [4, 49]. We also aimed to 
clarify whether the guardian vendor will have a substitutional or a complementary effect on the client's IP capacities.

Using an international data set of 189 IT multi-sourcing arrangements, we found that two internal IP capacities complement each other. Indeed, the client's formal intervendor governance and the client's architectural knowledge positively affect joint performance, while informal inter-vendor governance has a significant effect on joint performance only when interacting with high architectural knowledge. With regard to the external source of IP capacity, we found that a guardian vendor complements the client's formal and informal inter-vendor governance while substituting the client's architectural knowledge. Thus, the guardian model is beneficial in settings where the client provides the formal framework for the guardian vendor to interact with the other vendors, where the client remains involved in this interaction, and where the client lacks architectural knowledge. This implies that, contrary to what has been suggested in the existing literature (i.e., [49] and [4]), the role of the guardian vendor may be more fruitfully understood as one of an architect rather than a mediator. The guardian compensates for the client's knowledge gaps, while the client still needs to engage in formal and informal governance of all vendors.

Next, we provide theoretical foundations and develop hypotheses. We then explain the method and findings, followed by a discussion of the results and their implications for research and practice.

\section{THEORETICAL BACKGROUND}

\section{The Information Processing View and Multi-Sourcing}

The Information Processing View (IPV) is a broad theoretical perspective that views entities (e.g., people, teams, organizations, and inter-organizational relationships) as information processing (IP) systems, and explains the structures and behaviors of these 
systems by referring to their IP limitations $[15,25]$. An important property of IP systems is their IP capacity, broadly defined as their ability to interpret, integrate, store, and transmit information [32 (p.42)]. One prominent stream of IPV research [15, 32] focuses on the IP capacity that is generated by governance mechanisms, namely "mechanisms for coordination and control" [48 (p. 618)]. Governance mechanisms, such as goal setting, planning, and direct interaction, generate IP capacity because they provide the information infrastructure through which the constituent elements of IP systems align actions (i.e., achieve coordination) and interests (i.e., achieve cooperation) [2, 5, 37]. A second stream of IPV research focuses on IP capacity generated by knowledge. It draws on a cognitive IP perspective to argue that IP capacity depends on existing knowledge, because existing knowledge provides the infrastructure that enables humans to assimilate and integrate new information $[9,13]$. Building on these two streams, we seek to examine how IP capacity within the multi-sourcing environment affects joint performance.

Indeed, the use of the IPV appears particularly suited to the context of multi-sourcing in light of the following four gaps. First, multi-sourcing research lacks an overarching theory that fits with the idiosyncrasies of multi-sourcing as opposed to single-sourcing. In our view, what makes multi-sourcing unique is its inherent complexity, which is based on interdependencies between vendors - as opposed to the client-vendor interdependencies of dyadic outsourcing. While IPV has been applied to studying dyadic relationships [e.g., 5, 32], where IP requirements may substantially vary from case to case, we argue that triadic settings, such as multi-sourcing, add a layer of complexity that warrants focus on the composition of IP capacities. The interdependencies that exist between tasks allocated to multiple vendors pose significant IP requirements for the client. In particular, in comparison to single- 
sourcing, the need to integrate sub-services or tasks outsourced to different vendors into a coherent whole creates additional IP requirements in multi-sourcing. Therefore, it is imperative to understand joint performance by modeling and testing the effects of certain IP capacities available within the multi-sourcing arrangement.

Second, the two streams of IPV research, one focusing on governance and the other on knowledge as sources of IP capacity, have mostly been developed in isolation. Consequently, understanding the relationship between architectural knowledge and governance in multi-sourcing and how these two IP capacities interact is imperative for both IS outsourcing and IPV research knowledge.

Third, the IS outsourcing literature [40] and the literature on multi-sourcing have, so far, mostly treated performance as an aggregate of the performances of the individual vendors [e.g., 20]. In this paper, however, we emphasize that what makes multisourcing unique is that performance consists of more than the sum of the contributions of individual vendors. As such, it is imperative to develop an understanding of the combined or joint performance, rather than the individual contributions of the vendors. Last but not least, the few references in the extant academic and professional ${ }^{4}$ literature to the role that the guardian vendor plays in multi-sourcing settings [4, 49] raise questions about the contribution of this actor to joint performance. We argue that the guardian brings its own unique set of IP capacities that can either complement or substitute the IP capacities provided by the client ${ }^{5}$.

\section{The Client's Challenge: With or Without a Guardian Vendor}

IP capacity can be provided by either the client or the guardian vendor, if the client has

\footnotetext{
${ }^{4} \mathrm{http}: / /$ www.computerweekly.com/blog/lnvestigating-Outsourcing//T-sourcing-models-are-shifting-A-Deloitte-perspective.

${ }^{5}$ As put by Tiwana [46], "Two things are complements if more of one increases the benefits of using the other. They are substitutes if more of one diminishes the benefits of using the other" ( $p .88)$.
} 
appointed one vendor to act as guardian (see Figure $1 b^{6}$ ). In the direct model (see Figure 1a), the client takes full responsibility for managing the vendors. In the guardian model, the client transfers some responsibilities to the guardian vendor. We argue that each model has important implications for the IP capacities needed to achieve a high joint performance.

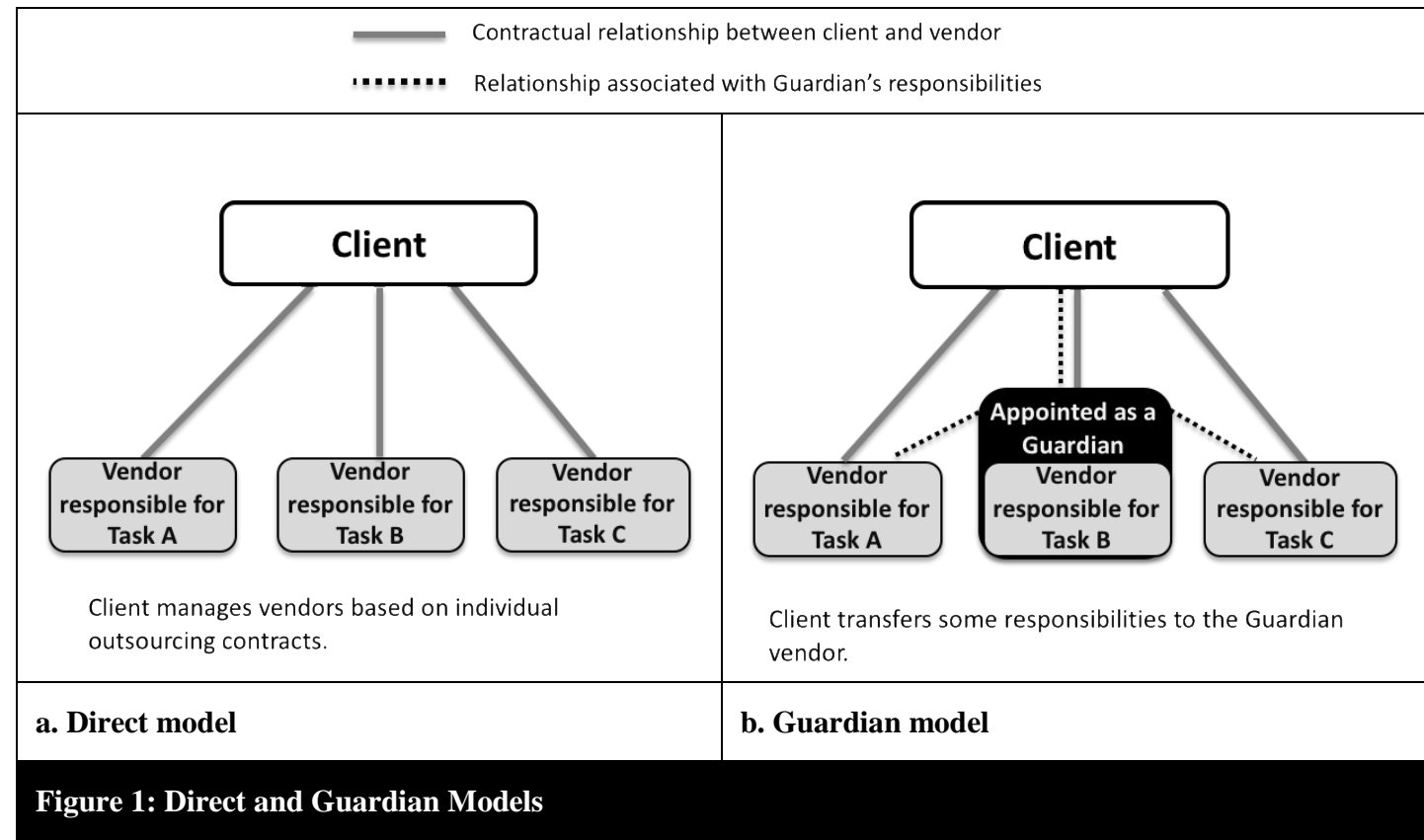

In the direct model, the client relies on two sources of IP capacity, namely governance and architectural knowledge. Governance in dyadic outsourcing relationships often manifests as formal and informal governance between a client and a vendor [36]. However, in multi-sourcing, informal and formal governance are likely to be required to support the coordination of actions between multiple vendors, thus suggesting a need for inter-vendor governance, i.e., joint governance structures between the multiple

\footnotetext{
${ }^{6}$ This is different from situations where the prime contractor is used, because in such a scenario the prime contractor is the only vendor contracted by the client and thus responsible for delivering the service. In the academic and professional literature, the prime contractor model "consists of a network with several vendors that operate under the control of the head contractor. The head contractor is accountable for the delivery of the service and liable for this under the terms of the contract" [34, p.134]. For example, Koo et al. [29] refer to the prime contractor outsourcing configuration as the "single-vendor-dominant model" where "a client directly contracts with one dominant vendor and indirectly contracts with other vendors through the dominant vendor" ( $p$. 3). Such contracting should not be confused with a true multi-sourcing scenario, where each vendor is contracted directly by the client firm, as depicted in Figure 1a.
} 
vendors and the client firm. In line with the psychological IPV research stream, we argue that information processing requires appropriate knowledge to guide governance, in particular the client's architectural knowledge [24, 38, 43].

While the conditions for achieving joint performance by utilizing the client's IP capacities are clear, it is still unclear how the choice of a guardian model affects these conditions. Currently, the few IS outsourcing studies that have discussed the guardian role suggest the guardian acts as a mediator, i.e., as an actor standing between the client and the rest of the vendors, thus relieving the client from facilitating coordination and cooperation between vendors $[4,49]$. To perform such a role, the guardian brings in its own IP capacity. From the client's perspective, therefore, the guardian acts as an external source of IP capacity, applying its own inter-vendor governance as well as its own architectural knowledge.

However, the view of guardian vendor as a mediator can be challenged. As reported in numerous sources ${ }^{7}$, the client maintains an individual contractual agreement with each vendor in the multi-sourcing setting, while the guardian vendor does not have legally binding contractual agreements with any of the vendors. Consequently, the guardian vendor's ability to enforce inter-vendor governance is in fact rather limited, particularly as the guardian vendor is restricted in the range of penalties and incentives it can use when governing the other vendors. Hence, it is unclear whether the guardian vendor does indeed assume a mediating role, as proposed in the literature [e.g., 4, 49]. Evidence from similar settings in manufacturing and construction predominantly suggests that the guardian vendor brings in superior knowledge about integrating the various contributions of individual vendors [7]. As such, an alternative view to the role of the guardian as a mediator is the guardian as an architect. This describes the guardian

\footnotetext{
${ }^{7}$ E.g. https://www.slaughterandmay.com/media/2535633/multi-sourcing-a-different-way-of-contracting.pdf.
} 
vendor as assisting the client in managing the multi-sourcing arrangement by complementing the client's IP capacities, rather than substituting them.

Thus, there are two views of the guardian vendor's role in multi-sourcing. In one, the guardian substitutes the client's inter-vendor governance (guardian-as-a-mediator) and, in the other, the guardian vendor complements the client's inter-vendor governance (guardian-as-an-architect).

With this in mind, we now turn to theorizing the effect of internal and external sources of IP capacity on joint performance.

\section{HYPOTHESES}

In this section, we use the IPV lens to derive hypotheses aimed at examining the effect of internal and external sources of IP capacity on joint performance. Figure 2 depicts our conceptual model.

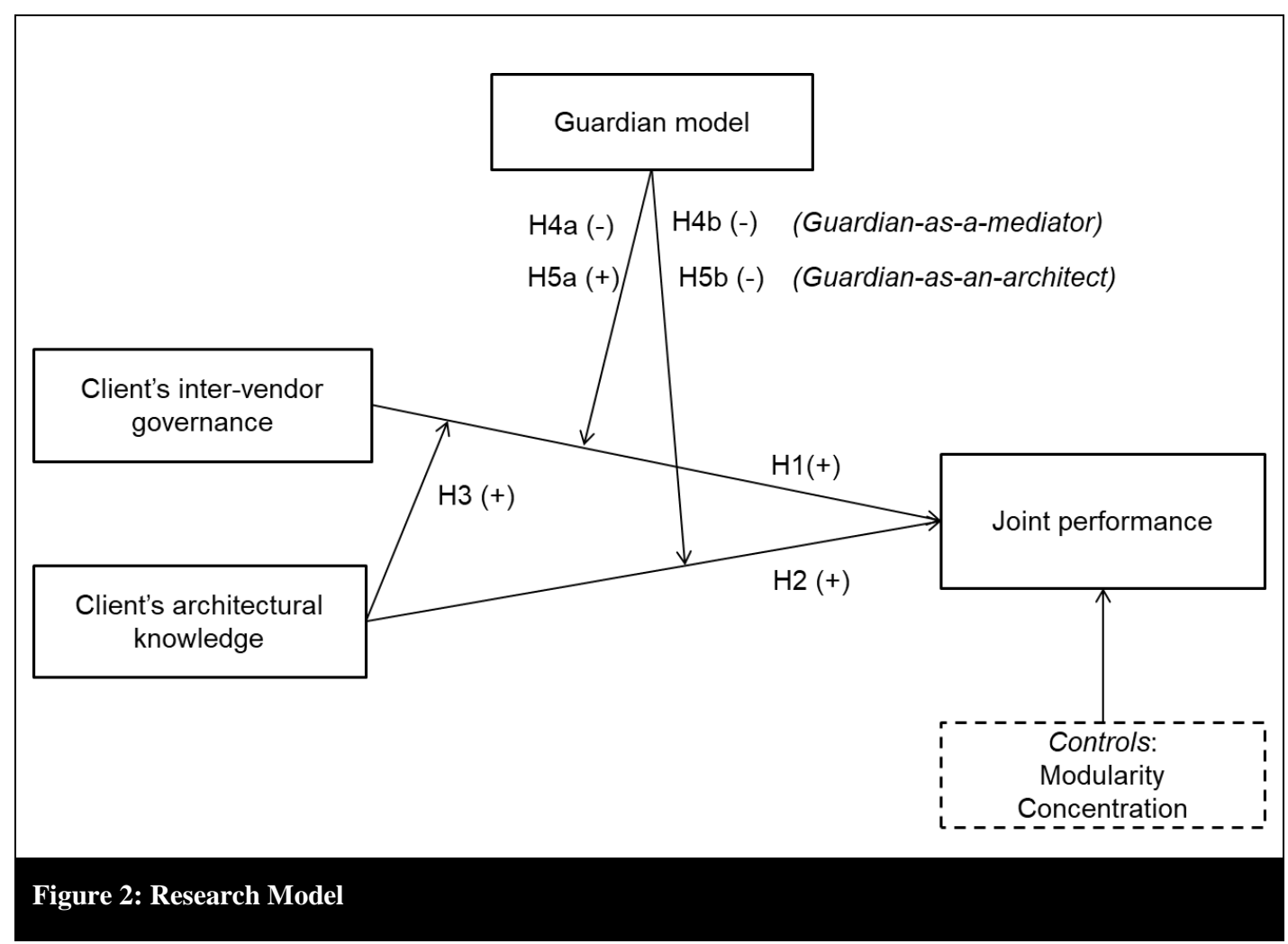




\section{The Client's Sources of Internal IP Capacity}

\section{The client's inter-vendor governance}

According to the IPV, governance is considered an important source of IP capacity [15]. In the context of multi-sourcing, it is manifested in inter-vendor governance efforts directed at achieving coordination and cooperation among multiple vendors. The literature distinguishes between formal and informal governance mechanisms $[26,36]$. Formal, or mechanistic, governance relies on pre-specified plans (or programs, procedures, and behaviors) and goals (or outcomes), and includes efforts toward specifying, monitoring, and enforcing these plans and goals. Thus, formal inter-vendor governance includes procedures that specify how vendors shall collaborate to achieve joint performance. As an example of a joint procedural mechanism, Wiener and Saunders [49] described how a client firm set up a support team made up of representatives from each vendor for the duration of the contract. In this type of formal arrangement, vendors' representatives are able to communicate with each other in order to coordinate work on interdependent tasks, while the client firm maintains communications with all vendors to ensure compliance with the contract requirements ${ }^{8}$. In contrast to such formal governance, informal or organic governance relies on ad hoc communication between people [36]. The IPV literature refers to informal governance as lateral relationships that allow for joint decision processes across levels of authority [15]. In the context of multi-sourcing, this means communication is facilitated across different hierarchical levels between the client and all vendors. Hence, we conceptualize informal inter-vendor governance as more or less frequently undertaken efforts for joint communication, i.e., communication involving the client and all vendors that cuts across different hierarchical levels. For example, client

\footnotetext{
8 https://www.information-age.com/how-to-make-multi-sourcing-work-123457348/
} 
representatives may meet with corresponding staff from all vendors in order to resolve accountability issues [49]. In line with prior IPV studies, we anticipate that both formal and informal inter-vendor governance generate IP capacity and as a result help to improve joint performance [14, 21, 26, 32]. Accordingly, we hypothesize:

H1: The stronger the client's formal and informal inter-vendor governance, the higher the joint performance.

\section{The client's architectural knowledge}

While the client can generate IP capacity through governance efforts to support coordination and cooperation between vendors, the cognitive stream of the IPV literature suggests that effective IP also depends on underlying knowledge. In this regard, in order to improve joint performance, it is imperative that the client brings in relevant knowledge on how the different services outsourced to different vendors should work together. Indeed, past research in the related domain of product development has shown that firms engaging in multi-sourcing have invested in developing abilities to integrate components delivered from various vendors [7, 24, 43]. Specifically, architectural knowledge is seen as a crucial resource that firms should retain or develop if choosing to source from multiple vendors [7, 43]. For example, in their analysis of specialization in knowledge production, Brusoni et al. [7] reported that although one manufacturer had fully outsourced the development of aircraft engine control systems to multiple vendors, the manufacturer still made significant efforts to develop and retain its architectural knowledge, i.e., "knowledge about the ways in which the components are integrated and linked together into a coherent whole" [23, p. 11]. Possessing such architectural knowledge improves the clients' ability to ensure joint performance in multi-sourcing arrangements [7, p. 614]. 
Thus, we argue that in addition to the governance efforts discussed above, a major factor determining a client's IP capacity for managing a multi-sourcing arrangement is the client's architectural knowledge. With the benefit of architectural knowledge, the client is then able to cope with the interdependencies between the outsourced sub-tasks and manage interfaces between services delivered by individual vendors. Therefore, we posit:

H2: The higher the degree of a client's architectural knowledge, the higher the joint performance.

The two sources of IP capacity discussed above - the client's inter-vendor governance and architectural knowledge - are likely to have complementary effects on joint performance. It is in inter-vendor governance efforts that the client can bring its knowledge to bear to improve the management of interdependencies. Knowledgeable clients are able to anticipate dependencies when they are specifying formal plans for joint action $[19,36]$. They may also have a greater ability to interpret information about actual behaviors or outcomes than less knowledgeable clients [7]. For example, they may be able to determine which vendor is accountable for a faulty delivery and leverage this information during formal and informal governance to avoid finger pointing [4]. Indeed Wiener and Saunders [49] illustrated such a case, arguing that "consistent with the competitive paradigm, when vendors are part of a sourcing arrangement involving multiple, interdependent vendors, they act in ways to make their performance look better than their competitors' and try to develop advantages over them (e.g., a vendor may seek to blame the other vendors for project or service delivery problems)" (p. 212). Resolving such conflict requires both governance and architectural knowledge [28]. A knowledgeable client, who well understands the nature of the interdependencies between the vendors, is likely to be able to apply appropriate informal and formal inter- 
vendor governance mechanisms that address the core of such conflict within the multisourcing arrangement. Clearly, lacking the required understanding of interdependencies would prevent the client firm from enacting appropriate inter-vendor governance mechanisms to resolve the problem. In sum, both formal and informal intervendor governing efforts are likely to be more effective for joint performance when the client has a strong architectural knowledge. Therefore, we hypothesize:

H3: A higher degree of architectural knowledge held by the client strengthens the positive association between inter-vendor governance and joint performance.

\section{A Guardian Vendor as a Source of External IP Capacity}

Our earlier examination of the guardian vendor's role suggests that the guardian may serve alternative purposes as a mediator or as an architect. The guardian in either role has differing implications for the client firm. For the guardian as a mediator, it is expected that the client firm would retreat from governance efforts now to be carried out by the guardian vendor. For the guardian as an architect, the client firm would retain governance effort while benefiting from the guardian's architectural knowledge. As the literature has so far only considered the guardian's mediator role, here we propose a competing explanation and seek to theorize the effect of each role on joint performance.

\section{The guardian-as-a-mediator perspective}

Viewing the guardian vendor as a mediator suggests that the guardian vendor is positioned between the client and the other vendor(s) in the multi-sourcing arrangement. Seen through an IPV lens, the guardian-as-a-mediator receives and interprets information from the client (such as information about the overall service expected from all the vendors working together), conveys the information to the other vendors, and receives, interprets, and conveys information from the vendors back to the client. 
In line with this perspective, Wiener and Saunders [49] argue that "the guardian vendor [...] coordinates the other vendors on the client's behalf' (p. 213). This assertion implies that the client retreats from inter-vendor governance, handing over this responsibility to the guardian vendor. The two internal sources of IP capacity, intervendor governance and the client's architectural knowledge, are then likely to become less important or even detrimental for joint performance.

Regarding the first, high amounts of inter-vendor governance by the client could even be detrimental to joint performance because confusion may arise if the guardian vendor believes it is to exercise inter-vendor governance, but the client continues to do so as well. A client who actively exercises inter-vendor governance would be at odds with the "single point of contact" [49, p. 213] principle inherent to the guardian-as-amediator perspective. Such parallel governance efforts are likely to result in coordination failures and accountability challenges.

The client's architectural knowledge is also likely to become less important with a guardian model based on the guardian-as-a-mediator perspective. Since the client retreats from inter-vendor governance, it is likely to have far fewer occasions to bring to bear its own knowledge. The occasions in which the client does bring to bear its own knowledge are then largely limited to interactions with the guardian vendor. So, although architectural knowledge may still be beneficial in helping to govern the guardian vendor more effectively, it is likely to be less critical than in the case of a direct model.

In sum, we argue that should the guardian assume the role of a mediator, it is plausible to suggest that the IP capacities of the client will be substituted by the IP capacity generated through the guardian model. We therefore assert that: 
H4a/b: The choice of the guardian model weakens the positive effects (a) of the client's inter-vendor governance and (b) of the client's architectural knowledge on joint performance.

\section{The guardian-as-an-architect perspective}

An alternative perspective to the guardian-as-a-mediator is the guardian-as-an-architect. This suggests that the guardian vendor contributes to joint performance by bringing in architectural knowledge that supports the client's governance efforts, rather than relieving the client from engaging in inter-vendor governance. In this perspective, the guardian vendor has a complementary relationship with the client regarding intervendor governance and a substitutive relationship with the client regarding architectural knowledge, as we will argue next.

According to the guardian-as-an-architect perspective, we expect a complementary relationship with the client's inter-vendor governance for two reasons. First, the guardian vendor brings in valuable knowledge, such as knowledge of governance structures effective for multi-sourcing relationships [31], and of the service architecture that underlies the multi-sourcing arrangement. As we argued earlier, knowledge is likely to make governance more effective $[7,28]$, as the client managers are able to leverage this knowledge to improve their inter-vendor governance. Second, while the guardian vendor may lack the formal authority and thus legitimacy to enact effective governance, the client maintains a high level of involvement in this capacity. Indeed, the client is the only party with legally binding contractual agreements with all the vendors $[4,12]$. High levels of inter-vendor governance by the client paired with a guardian model allow multi-sourcing arrangements to leverage the client's authority and the guardian vendor's knowledge at the same time. In sum, we expect that the external IP capacity generated through the knowledge brought in by the guardian will 
complement the internal IP capacity generated through the client's inter-vendor governance. These ideas echo Bapna et al.'s [4] view of the governance efforts of the client in the presence of a guardian vendor, in that: "[...] not only does the client still engage in multilateral contracts with multiple vendors but also has to consider the guardian's ability to ensure cooperation and coordination in determining its overall relationship structure" (p. 794).

In the guardian-as-an-architect perspective, while the guardian vendor complements the client's inter-vendor governance, it substitutes the client's architectural knowledge. Without the presence of a guardian vendor, the client requires strong architectural knowledge in order to exercise effective governance (e.g., to tackle accountability problems and to design effective plans for coordination). Conversely, the client's architectural knowledge is likely to be less critical (although still beneficial) in the presence of a guardian vendor. If a client lacks architectural knowledge, the guardian vendor can compensate by providing guidance on how to set up and exercise effective inter-vendor governance. Thus, the positive effect of the client's architectural knowledge on joint performance is likely to be weaker in the guardian model than in the direct model. This corresponds to a substitutive relationship [46, p. 88], whereby the benefits from the architectural knowledge held by the client decrease with the choice of the guardian model. Seen through the IPV, the external IP capacity generated through the guardian vendor's knowledge partially substitutes the internal IP capacity generated through the client's architectural knowledge. In conclusion, the guardian-asan-architect perspective leads us to the following hypothesis:

H5a/b: The choice of the guardian model (a) strengthens the positive effect of the client's governance on joint performance, while $(b)$ weakening the positive effect of the client's architectural knowledge on joint performance. 


\section{Control Variables}

While our research model focuses on sources of IP capacity and their interactions, we have also controlled for a number of other relationships established in the outsourcing and IPV literature. First, we controlled for modularity. Modularity refers to the degree to which the outsourced sub-tasks can be easily combined into a coherent whole [39, 44]. Outsourcing arrangements of high modularity rely on well-defined, standardized interfaces that facilitate the integration of the sub-tasks performed by the different parties $[3,6,44]$. From an IPV perspective, such modularity is a key determinant of IP requirements [44]. Modular arrangements may ease the composition and integration of sub-tasks outsourced to different vendors and, thereby, lower IP requirements. Accordingly, modularity may increase joint performance independent of the IP capacity available in a multi-sourcing arrangement. Second, in line with the existing IPV research, we controlled for interactions of IP requirements with sources of IP capacity $[2,32]$. Specifically, it can be argued that high modularity lowers the need for IP capacities to satisfy the client's expectations of joint vendor performance. We therefore controlled for interactions between modularity and formal and informal governance, the client's architectural knowledge, and the choice of the guardian model. Moreover, we controlled for concentration (i.e., the degree to which a large fraction of the project work is allocated to a few vendors) [27], age of the arrangement (i.e., the number of years since the creation of the multi-sourcing arrangement), client size (as indicated by the number of employees), client country, client industry, and tasks included in the arrangement (business process outsourcing, application development). We also controlled for the interaction between concentration and choice of the guardian model. Low concentration indicates that many vendors are involved in the multi-sourcing arrangement. The lower the concentration, the more difficult it may be for the guardian 
vendor to manage the large number of other vendors, suggesting a possible interaction effect between concentration and the choice of the guardian model.

\section{METHODS}

\section{Data}

We empirically tested the theoretical framework (Figure 2) using a survey questionnaire and "key informants" methodology for data collection [35], in line with past IS outsourcing studies [e.g., 17]. The data were collected in 2012 and 2013 with the help of a UK-based market research firm.

The questionnaire was administered to organizations across different countries, including the UK, Germany, France, Italy, Spain, and the US, and spanning a variety of industries. For this purpose, the original English version of the questionnaire was translated by the market research firm and checked by native speakers (chosen by the authors) who were familiar with the study context to ensure the correctness of the translation. Responses were collected using both telephone interviews and an online survey.

The questionnaire was distributed among potential middle and top-level informants who were familiar with multi-sourcing arrangements within their firms. To ensure the targeted individuals' familiarity with multi-sourcing arrangements (so qualifying them as a "key informant"), the respondents needed to answer a set of screening questions and meet the following criteria ${ }^{9}$ :

- Being employed by an organization with at least 250 employees,

\footnotetext{
${ }^{9}$ The market research firm used these criteria to select key informants from a panel of individuals that had agreed to participate in surveys.
} 
- Having an outsourcing arrangement(s) in place where the organization had consciously divided a task or project into particular sub-tasks or sub-projects that were outsourced to different vendors, and

- Having familiarity with the management of such a multi-sourcing arrangement in her or his company.

The respondent then had to select one particular multi-sourcing arrangement currently in place in their company and with which they were familiar. Within this particular multi-sourcing arrangement, the respondent was asked to select the two vendors contributing the most to the multi-sourcing arrangement (in terms of amount of work). The questions relevant for testing our model pertained only to this particular multisourcing arrangement with the two chosen vendors, subsequently called vendor A and B throughout the questionnaire. Our study and empirical testing thus focused on one particular "triad" within the multi-sourcing arrangement [10], each triad consisting of the client and two key vendors. Focusing on triads ensured that the unit of analysis was the same for all respondents.

Before sending out the final questionnaire, the questionnaire items were pilot-tested with 15 international organizations to ensure that all items could be understood and answered by the intended group of respondents. Each block of questions was followed by an open field for comments, where respondents were asked to note down any thoughts they had on the questions asked in the preceding section. The comments were considered in the refinement of the questionnaire and some amendments were introduced to improve the clarity of questions. In addition, we tested our model on the pilot data to assess the validity of the constructs. Items that loaded very low were removed from the questionnaire. 
The finalized questionnaire was sent out to 2000 organizations. Overall, 200 usable questionnaires were made available after several follow-ups with the sample organizations. From these 200 cases, we excluded 10 after reviewing the descriptions of outsourced tasks. We excluded cases when the sub-tasks assigned to different vendors were not interdependent (e.g., outsourcing IT procurement to vendor A and sales advice to vendor B), or when the outsourced tasks did not match our target services, which comprised IT services and IT-supported business processes. For example, in one case the services were "providing a camera crew" (vendor A) and "providing special equipment for camera crew services" (vendor B). We also excluded one outlier, which reported a joint performance of four standard deviations below the sample mean although the same firm reported above-average individual performance ${ }^{10}$ of the vendors, suggesting an erroneous measurement. Our final sample size was $n=189$. Table 1 shows the sample characteristics.

\section{Measures}

Each construct was measured with a block of indicators (questionnaire items). Where possible, we used existing measures that we adapted to the study context [43]. All items were measured on a five-point Likert scale, ranging from "strongly disagree" $(=1)$ to "strongly agree" (=5) with "neither agree nor disagree" $(=3)$ as the mid-point. An overview of the constructs and measurement items is provided in Table 2. Joint performance was measured by six items (developed in IS outsourcing research) that focused on the degree to which the joint performance of the two vendors met the client's expectations. Architectural knowledge was measured by three items that focused on the client's knowledge in relation to the integration of the services delivered by the two

\footnotetext{
10 The survey included three items measuring individual performance (composite reliability .87), which were not used for this study.
} 
vendors. Our measures of formal governance referred to the use of two key formal governance strategies in the IPV, i.e., procedures and goals [15, p.43-46]. The measures focused on the client's efforts for specifying joint procedures and goals and for evaluating the vendors' adherence to the procedures and goals. Our measures of informal governance focused on what IPV researchers call lateral relations, i.e., "direct contact between two people who share a problem" at the same hierarchical level [15, p.53]. These measures, adapted from Takeishi [43], assessed the amount of direct contact at three levels: IT staff, middle management, top management. To assess whether a guardian vendor model was chosen, we asked whether one of the two vendors was responsible for managing other vendors. The measures for our control variable modularity were taken from Tanriverdi et al. [44]. Table 3 provides an overview of the measures for control variables.

\begin{tabular}{|c|c|c|c|}
\hline \multicolumn{2}{|c|}{ Characteristics of the Sample } & \multirow{2}{*}{$\frac{[\text { Min; Max }]}{[.5 ; 35]}$} & \multirow{2}{*}{$\frac{\text { Mean (Std. Dev.) }}{8.6(6.5)}$} \\
\hline $\begin{array}{l}\text { Respondent work } \\
\text { experience }\end{array}$ & Number of years working in organization & & \\
\hline \multirow[t]{2}{*}{$\begin{array}{l}\text { Age of multi-sourcing } \\
\text { arrangement }\end{array}$} & $\begin{array}{l}\text { Years that have passed since the start of the } \\
\text { multi-sourcing arrangement }\end{array}$ & {$[1 ; 9]$} & $3.7(2.4)$ \\
\hline & & Number & Percentage \\
\hline \multirow{4}{*}{ Client size } & Up to 1,000 employees & 70 & $37 \%$ \\
\hline & 1,001 to 5,000 employees & 61 & $32 \%$ \\
\hline & 5,001 to 50,000 employees & 46 & $24 \%$ \\
\hline & More than 50,000 employees & 12 & $6 \%$ \\
\hline \multirow{6}{*}{ Country } & United Kingdom & 33 & $17 \%$ \\
\hline & France & 31 & $16 \%$ \\
\hline & Germany & 33 & $17 \%$ \\
\hline & Italy & 32 & $17 \%$ \\
\hline & Spain & 30 & $16 \%$ \\
\hline & USA & 30 & $16 \%$ \\
\hline \multirow{5}{*}{ Industry sector } & Financial services & 34 & $18 \%$ \\
\hline & Manufacturing & 39 & $21 \%$ \\
\hline & Retail, distribution and transport & 25 & $13 \%$ \\
\hline & Public sector & 35 & $19 \%$ \\
\hline & Other & 56 & $30 \%$ \\
\hline \multirow{8}{*}{$\begin{array}{l}\text { Respondent's area of work } \\
\text { within client firm }\end{array}$} & Owner/executive & 22 & $12 \%$ \\
\hline & Finance & 18 & $10 \%$ \\
\hline & IT & 103 & $54 \%$ \\
\hline & Facilities & 5 & $3 \%$ \\
\hline & Marketing & 7 & $4 \%$ \\
\hline & Customer services & 15 & $8 \%$ \\
\hline & Human resources & 10 & $5 \%$ \\
\hline & Logistics & 9 & $5 \%$ \\
\hline
\end{tabular}


Table 2: Questionnaire Items (CR = composite reliability, AVE = average variance extracted $)$

\begin{tabular}{|c|c|c|c|}
\hline Construct & Item & Wording & Reference \\
\hline \multirow{7}{*}{$\begin{array}{l}\text { Joint performance } \\
(\mathrm{CR}=.90, \mathrm{AVE} \\
=.61)\end{array}$} & & $\begin{array}{l}\text { With regard to combined performance of vendor A and vendor B as part } \\
\text { of the multi-sourcing arrangement so far... }\end{array}$ & \\
\hline & JP1 & ... the products/services delivered meet our expectations. & \multirow{4}{*}{$\begin{array}{l}\text { Grover et al. } \\
{[21]}\end{array}$} \\
\hline & JP2 & ... we have met our goals. & \\
\hline & JP3 & ... we have completed key milestones in accordance with our objectives. & \\
\hline & JP4 & ... we have achieved our desired cost savings. & \\
\hline & JP5 & ... we are satisfied with our overall benefits from outsourcing. & $\begin{array}{l}\text { Lee and Kim } \\
{[30]}\end{array}$ \\
\hline & JP6 & ... we have so far met project/service requirements. & Tiwana [45] \\
\hline \multirow{4}{*}{$\begin{array}{l}\text { Architectural } \\
\text { knowledge }(\mathrm{CR}= \\
.88, \mathrm{AVE}=.72)\end{array}$} & & $\begin{array}{l}\text { The following questions are related to the level of knowledge of you and } \\
\text { your in-house colleagues. We have knowledge about ... }\end{array}$ & \\
\hline & AK1 & $\begin{array}{l}\ldots \text { the design of the overall product and service architecture to which } \\
\text { vendors A and B contribute. }\end{array}$ & \multirow[t]{2}{*}{ Takeishi [43] } \\
\hline & AK2 & $\begin{array}{l}\ldots \text { how to structurally coordinate the products and services delivered by } \\
\text { vendors A and B with all other related products and services of our } \\
\text { organization. }\end{array}$ & \\
\hline & AK3 & $\begin{array}{l}\ldots \text { the ways in which the products and services delivered by vendors } \mathrm{A} \\
\text { and } \mathrm{B} \text { are integrated and linked together in a coherent whole. }\end{array}$ & $\begin{array}{l}\text { Henderson and } \\
\text { Clark [23] }\end{array}$ \\
\hline \multirow[t]{8}{*}{$\begin{array}{l}\text { Formal } \\
\text { governance }(\mathrm{CR} \\
=.90, \mathrm{AVE}= \\
.63)\end{array}$} & & $\begin{array}{l}\text { To ensure that it is not the individual performance of vendor A and B, } \\
\text { but rather their combined performance (i.e., solutions by vendor A and B } \\
\text { in combination as part of the multi-sourcing arrangement) that meets our } \\
\text { objectives, we ... }\end{array}$ & \multirow[t]{8}{*}{$\begin{array}{l}\text { Kirsch et al. } \\
{[28]}\end{array}$} \\
\hline & FG1 & $\begin{array}{l}\text {... expect both vendors to follow an understandable written sequence of } \\
\text { steps that defines interactions between these two vendors. }\end{array}$ & \\
\hline & FG2 & $\begin{array}{l}\ldots \text { assess the extent to which both vendors interact in accordance to } \\
\text { existing written procedures and practices when delivering the outsourced } \\
\text { service. }\end{array}$ & \\
\hline & FG3 & $\begin{array}{l}\text {... evaluate the extent to which combined services are delivered as } \\
\text { defined in the contract regardless of how this goal is accomplished. }\end{array}$ & \\
\hline & FG4 & $\begin{array}{l}\ldots \text { test intermediary and/or final joint outcomes/deliverables against } \\
\text { criteria defined in the contract, regardless of how this goal is achieved. }\end{array}$ & \\
\hline & FG5 & ... have several sources of objective data we can rely on. & \\
\hline & FG6 & $\begin{array}{l}\text {... have defined quantifiable measures depicting the extent to which } \\
\text { combined objectives are achieved. }\end{array}$ & \\
\hline & FG7 & $\begin{array}{l}\ldots \text { have defined accurate and reliable measures that indicate the extent to } \\
\text { which the delivered services jointly meet our objectives. }\end{array}$ & \\
\hline \multirow{3}{*}{$\begin{array}{l}\text { Informal } \\
\text { governance }(\mathrm{CR} \\
=.86, \mathrm{AVE}= \\
.66)\end{array}$} & IG1 & Our IT staff interact jointly with both vendors' IT personnel. & \multirow[t]{3}{*}{ Takeishi [43] } \\
\hline & IG2 & $\begin{array}{l}\text { Our middle managers interact jointly with both vendors' middle } \\
\text { managers. }\end{array}$ & \\
\hline & IG3 & $\begin{array}{l}\text { Our top managers/executives interact jointly with both vendors' top } \\
\text { managers/executives. }\end{array}$ & \\
\hline $\begin{array}{l}\text { Guardian versus } \\
\text { Direct (single } \\
\text { item) }\end{array}$ & GU & $\begin{array}{ll}\text { Are either of the two vendors responsible for managing all other vendors } \\
\text { in the multi-sourcing arrangement? } \\
\begin{array}{ll}\text { - Yes, vendor A } & \rightarrow \text { Guardian } \\
\text { - Yes, vendor B } & \rightarrow \text { Guardian } \\
\text { - No, this is our responsibility } & \rightarrow \text { Non-guardian } \\
\text { - Other (please explain) } & \rightarrow \text { Manually coded }^{11}\end{array}\end{array}$ & Self-developed \\
\hline \multirow{3}{*}{$\begin{array}{l}\text { Modularity }(\mathrm{CR} \\
=.81, \mathrm{AVE}=.68)\end{array}$} & & Regarding the two tasks/projects outsourced to vendor A and $\mathrm{B}, \ldots$ & \\
\hline & MO1 & $\begin{array}{l}\ldots \text { it is very easy to combine their particular outcomes into a coherent } \\
\text { whole. }\end{array}$ & \multirow[t]{2}{*}{$\begin{array}{l}\text { Tanriverdi et } \\
\text { al. [44] }\end{array}$} \\
\hline & $\mathrm{MO} 2$ & ... they have well-defined interfaces with each other. & \\
\hline
\end{tabular}

\footnotetext{
${ }^{11}$ Only one respondent selected the "Other" category. The comment suggested than a third vendor (not vendor A or B) was responsible for managing the other vendors. We therefore coded this response as a guardian model.
} 


\section{Table 3: Control Variables}

\begin{tabular}{|l|l|}
\hline Variable & Measurement \\
\hline Concentration & $\begin{array}{l}\text { The fraction of the overall budget of the multi-sourcing arrangement } \\
\text { that is assigned to vendors A and B; measured through a single-item } \\
\text { question }\end{array}$ \\
\hline Modularity & Measured through two questionnaire items (see Table 2) \\
\hline Age of the multi-sourcing arrangement & $\begin{array}{l}\text { The number of years since the start of the multi-sourcing } \\
\text { arrangement; measured through a single-item question }\end{array}$ \\
\hline Client size & $\begin{array}{l}\text { The client's number of employees; measured through a single-item } \\
\text { question (transformation: natural logarithm) }\end{array}$ \\
\hline Country & $\begin{array}{l}\text { Single-item question on the client's country (United Kingdom, } \\
\text { Germany, Italy, Spain, USA, France); incorporated through five } \\
\text { dichotomous dummy variables (reference category: France) }\end{array}$ \\
\hline Industry & $\begin{array}{l}\text { Single-item question on the client's sector (financial services, } \\
\text { manufacturing, retail, public sector, other); incorporated through four } \\
\text { dichotomous dummy variables (reference category: Other) }\end{array}$ \\
\hline Business Process Outsourcing (BPO) & $\begin{array}{l}\text { Indicates whether business processes (other than IT) were part of the } \\
\text { outsourced tasks; coded based on task descriptions }\end{array}$ \\
\hline Application Development & $\begin{array}{l}\text { Indicates whether the development of application software was part } \\
\text { of the outsourced tasks; coded based on task descriptions }\end{array}$ \\
\hline
\end{tabular}

\section{Instrument Validation}

To validate our survey instrument, we assessed convergent and discriminant validity through factor analysis procedures. To examine convergent validity, we first performed an exploratory factor analysis in SPSS. This analysis reproduced the five latent factors of our research model with eigenvalues greater than 1.6. Eigenvalues greater than 1 suggest convergent validity [16]. To further corroborate convergent validity, we calculated composite reliability (CR), average variance extracted (AVE), and standardized factor loadings, using confirmatory factor analysis procedures in SmartPLS [16]. CR was well above the threshold of .7 for all constructs (see Table 2). AVE was well above the threshold of .5 for all constructs (see Table 2). The standardized factor loadings were greater than .7 with the exceptions of FG1 (.66) and FG4 (.65), which were close to the threshold. These two slightly lower values could be due to our attempt to capture formal governance as broadly and comprehensively as possible. By and large, the measurement evidence supports convergent validity. 
We then examined discriminant validity. We tested whether each item loaded higher on its construct than on any other construct [16]. For each item, the difference between the loading of the item on its construct and the cross-loading of the item on any other construct was above .2. Moreover, we examined whether the square roots of the AVE values exceeded correlations between latent constructs [16]. The square root of the lowest AVE value (.75 for formal governance) was well above the highest correlation between two latent constructs (.60 for the correlation between joint performance and formal governance). These results, and the fact that exploratory factor analysis reproduced the five latent factors, strongly support discriminant validity.

\section{Regression Analysis}

We used a regression approach to test our hypotheses. Given our focus on interaction effects, we chose regression over alternative approaches, such as partial least squares (PLS) and covariance-based structural equation modeling (SEM). Regression offers higher statistical power for detecting interaction effects than PLS or covariance-based SEM [18]. The advantage gained in statistical power is particularly pronounced in models such as ours, in which many items are subject to interaction effects [18, p. 222]. We relied on standardized mean scores to transform sets of items into regression variables.

We used a four-step hierarchical regression strategy. In the first step (Model 1), we included the main effects of control variables. In the second step (Model 2), we added the main effects of the hypothesized predictors. In the third step (Model 3), we added the interactions of IP requirements (i.e., modularity) with sources of IP capacity (i.e., formal and informal governance, architectural knowledge, guardian model) to control for interaction effects established in the IPV research. In the fourth step (Model 4), we added the hypothesized interaction effects. 
We examined whether the assumptions of regression analyses were met [50, pp. 104105]. The histograms and $\mathrm{q}-\mathrm{q}$ plots showed that the residuals followed normal distributions, indicating that the assumption of normally distributed error terms was met. Variance inflation factors were below 3, suggesting that multicollinearity problems were not salient in the data. Plotting residuals and joint performance in a scatter plot diagram showed no departure from the assumption of homoscedastic error terms.

Although our study focused on interaction effects which cannot be artifacts of commonmethod variance [e.g., 41], we performed Harman's single factor test to appreciate whether item responses varied due to one single factor. We found that a single factor was able to explain $26 \%$ of the variance and that five factors were needed to explain half of the variance. Given these results and our focus on interaction effects, it is unlikely that the findings reported in this study are artifacts of common-method variance.

To assess potential endogeneity threats in our analysis, we estimated alternative models based on Heckman correction for self-selection. Specifically, it is possible that clients self-select the guardian model based on factors that also correlate with joint performance (e.g., vendor capability). This could result in biased, inconsistent estimates [22]. Following prior research on governance [32], we performed the following steps to correct for the potentially endogenous choice of the guardian model. First, we estimated a first-stage probit selection model that regressed the choice of the guardian model on all main-effect predictors of the second-stage model and on BPO. BPO served as an exclusion restriction, i.e., as a variable that helps predict the selection variable (i.e., choice of the guardian model) but does not correlate with the dependent variable (i.e., joint performance)[11]. We chose BPO as our exclusion restriction because the 
guardian model has only recently gained popularity in IS outsourcing. Hence, we expected that BPO arrangements would make greater use of the guardian model than IS outsourcing arrangements, while we had no reason to expect that BPO arrangements would differ from IS outsourcing arrangements in their level of joint performance. In line with these ideas, BPO correlated strongly with the choice of the guardian model $(\beta=.82 ; p<.01)$ but not with joint performance $(p>.05)$. Second, we calculated the inverse Mills ratio for each observation as follows:

$\lambda_{1 i}=\frac{\varphi\left(\beta^{\prime} X_{i}\right)}{\phi\left(\beta^{\prime} X_{i}\right)}$ for arrangements that chose a guardian model

$\lambda_{0 i}=-\frac{\varphi\left(\beta^{\prime} X_{i}\right)}{\left(1-\phi\left(\beta^{\prime} X_{i}\right)\right)}$ for arrangements that chose a direct model

where $\lambda_{j i}$ is the inverse Mills ratio, $\varphi$ the standard normal probability density function, $\beta^{\prime}$ the vector of regression coefficients estimated by the probit selection model and $\phi$ the cumulated standard normal probability function. Third, we included the inverse Mills ratio as a control variable in the second-stage model predicting joint performance. The Heckman correction approach helps control for the client's propensity to choose a guardian model. Moreover, the regression coefficient related to the inverse Mills ratio serves as an indicator for the presence of endogeneity. If the coefficient is significantly different from 0 , this indicates that endogeneity is present and, hence, should be corrected for by including the inverse Mills ratio as a control variable. We estimated alternative models based on Heckman correction (Model 2b, 3b, 4b) for each model that contained the guardian model as a predictor (i.e., Model 2a, 3a, 4a).

To examine nonresponse bias, we compared the means of eight key variables (joint performance, modularity, concentration, age of the arrangement, formal governance, informal governance, architectural knowledge, guardian) between multi-sourcing arrangements that were in our sample and multi-sourcing arrangements not included in 
the sample (most frequently due to the respondents' lack of willingness to provide descriptions of the outsourced tasks). Comparisons revealed no significant differences with the exception of formal governance, which was somewhat higher in the arrangements included in the final sample than in those excluded (3.99 vs. 3.82; t test; $\mathrm{n}=369 ; \mathrm{p}<.05)$. With only one of eight comparisons yielding a significant difference, we inferred that nonresponse bias was unlikely to be a serious threat to the validity of our analysis.

\section{RESULTS}

Table 4 shows descriptive statistics, separated by guardian versus direct subsamples. The only significant differences referred to business process outsourcing, which was more frequent in the guardian sample, and informal governance, which was stronger in the guardian sample. Table 5 presents bivariate correlations.

\begin{tabular}{|c|c|c|c|}
\hline & $\begin{array}{l}\text { Direct sample: Mean } \\
\text { (standard deviation) }\end{array}$ & $\begin{array}{c}\text { Guardian sample: Mean } \\
\text { (standard deviation) }\end{array}$ & $\begin{array}{c}\text { Difference statistically } \\
\text { significant }\end{array}$ \\
\hline Joint performance & $4.06(.65)$ & $4.02(.75)$ & No \\
\hline Concentration & $52.17(31.49)$ & $55.63(29.28)$ & No \\
\hline Modularity & $3.72(.83)$ & $3.96(.88)$ & No \\
\hline Age of arrangement & $3.76(2.44)$ & $3.44(2.29)$ & No \\
\hline Client size & $7.88(1.80)$ & $8.03(1.56)$ & No \\
\hline Business process outsourcing & $.56(50)$ & $.82(.38)$ & Yes $(\mathrm{p}<.05)$ \\
\hline Application development & $.20(.40)$ & $.11(.31)$ & No \\
\hline Formal governance & $3.93(.74)$ & $4.12(.56)$ & No \\
\hline Informal governance & $2.73(1.06)$ & $3.12(.96)$ & Yes $(\mathrm{p}<.05)$ \\
\hline Architectural knowledge & $4.03(.76)$ & $4.19(.66)$ & No \\
\hline Sub-sample size (n) & 132 & 57 & - \\
\hline
\end{tabular}

Table 5: Bivariate Correlations (*p $<.05)$

\begin{tabular}{|c|c|c|c|c|c|c|c|c|c|c|c|}
\hline & $\begin{array}{l}\text { Joint } \\
\text { perf. }\end{array}$ & Con. & Mo. & Age & $\begin{array}{l}\mathrm{Cl} . \\
\text { size }\end{array}$ & BPO & $\begin{array}{l}\text { App. } \\
\text { Dev. }\end{array}$ & Grd. & $\begin{array}{l}\text { Form. } \\
\text { gov. }\end{array}$ & $\begin{array}{l}\text { Inf. } \\
\text { gov. }\end{array}$ & $\begin{array}{l}\text { Arch. } \\
\text { knowl. }\end{array}$ \\
\hline Joint performance & 1 & & & & & & & & & & \\
\hline Concentration & .03 & 1 & & & & & & & & & \\
\hline Modularity & $.44 *$ & $.13 *$ & 1 & & & & & & & & \\
\hline Age of arrangement & .07 & -.09 & .07 & 1 & & & & & & & \\
\hline Client size & -.05 & .08 & .05 & $.20 *$ & 1 & & & & & & \\
\hline $\mathrm{BPO}$ & .12 & .10 & $.15^{*}$ & $.14 *$ & -.10 & 1 & & & & & \\
\hline Appl. Development & -.12 & -.10 & -.12 & -.03 & .05 & $-.38 *$ & 1 & & & & \\
\hline Guardian & -.02 & .05 & .13 & -.06 & .04 & $.25 *$ & -.12 & 1 & & & \\
\hline Formal governance & $.58 *$ & .03 & $.40^{*}$ & .01 & -.07 & .13 & -.14 & .12 & 1 & & \\
\hline Informal governance & .12 & .09 & .09 & .11 & .04 & .12 & .00 & $.17 *$ & $.15 *$ & 1 & \\
\hline $\begin{array}{l}\text { Architectural } \\
\text { knowledge }\end{array}$ & $.52 *$ & -.10 & $.29 *$ & .04 & .07 & .03 & -.01 & .10 & $.57 *$ & $.16^{*}$ & 1 \\
\hline
\end{tabular}


The results of our four-step regression are presented in Table 6. The first column

(Model 1) presents results related to our control variables. Modularity $(\beta=.44 ; p<.001)$

had significant positive associations with joint performance while the other control variables shown in Table 6 were insignificant.

\begin{tabular}{|c|c|c|c|c|}
\hline & Model 1 & Model 2a & Model 3a & Model 4a \\
\hline (Constant) & $-.29(.23)$ & $-.13(.19)$ & $-.03(.19)$ & $-.13(.19)$ \\
\hline Concentration & $-.03(.07)$ & $.02(.06)$ & $.15 *(.07)$ & $.17 *(.07)$ \\
\hline Modularity & $.43^{* * * *}(.07)$ & $.23 * * *(.06)$ & $.25 * *(.08)$ & $.24 * *(.08)$ \\
\hline Age of arrangement & $-.02(.07)$ & $-.01(.06)$ & $.01(.06)$ & $.01(.06)$ \\
\hline Client Size & $-.06(.07)$ & $-.04(.06)$ & $-.06(.06)$ & $-.04(.06)$ \\
\hline Business Process Outsourcing & $.06(.16)$ & $.10(.14)$ & $.08(.14)$ & $.06(.13)$ \\
\hline $\begin{array}{l}\text { Application Development } \\
\text { Inverse Mills Ratio }\end{array}$ & $-.11(.19)$ & $-.08(.16)$ & $\begin{array}{r}-.08(.16) \\
-\end{array}$ & $\begin{array}{r}-.07(.15) \\
-\end{array}$ \\
\hline Guardian & - & $-.31 *(.13)$ & $-.32 *(.13)$ & $-.37 * *(.13)$ \\
\hline Formal governance & - & $.31 * * *(.07)$ & $.26 * * *(.07)$ & $.18 *(.08)$ \\
\hline Informal governance & - & $.00(.06)$ & $.02(.06)$ & $-.07(.06)$ \\
\hline Architectural knowledge & - & $.29 * * *(.07)$ & $.34 * * *(.07)$ & $.46^{* * *}(.08)$ \\
\hline Modularity $\times$ Guardian & - & - & $.00(.13)$ & $-.04(.14)$ \\
\hline Modularity $\times$ Formal governance & - & - & $-.11(.07)$ & $-.12(.07)$ \\
\hline Modularity $\times$ Informal governance & - & - & $.06(.05)$ & $-.02(.06)$ \\
\hline Modularity $\times$ Client's architectural knowledge & - & - & $.02(.07)$ & $.03(.07)$ \\
\hline Concentration $\times$ Guardian & - & - & $-.42 * *(.13)$ &.$- .46 * * *(.13)$ \\
\hline $\begin{array}{l}\text { Formal governance } \times \text { Client's architectural } \\
\text { knowledge }\end{array}$ & - & - & - & $-.01(.06)$ \\
\hline $\begin{array}{l}\text { Informal governance } \times \text { Client's architectural } \\
\text { knowledge }\end{array}$ & - & - & - & $.13 *(.06)$ \\
\hline Guardian $\times$ Formal governance & - & - & - & $.42 *(.19)$ \\
\hline Guardian $\times$ Informal governance & - & - & - & $.38 * *(.14)$ \\
\hline Guardian $\times$ Client's architectural knowledge & - & - & - & $-.52 * *(.17)$ \\
\hline Adjusted $\mathrm{R}^{2}$ & .21 & .44 & .47 & .51 \\
\hline $\mathrm{R}^{2}$ & .27 & .49 & .54 & .59 \\
\hline$\Delta \mathrm{R}^{2}$ & .27 & .22 & .05 & .05 \\
\hline F Change (d.f.) & $\begin{array}{r}4.34 * * *(15 \\
173)\end{array}$ & $\begin{array}{r}18.33 * * * \\
(4,169)\end{array}$ & $\begin{array}{r}3.20 * * *(5 \\
164)\end{array}$ & $3.63 * *(5,159)$ \\
\hline
\end{tabular}

The second column (Model 2a) shows the main effects of our four predictors (i.e., the sources of IP capacity), allowing us to test $\mathrm{H} 1$ and $\mathrm{H} 2$. $\mathrm{H} 1$ predicts positive main effects for formal and informal governance on joint performance. We found a significant positive effect for formal governance $(\beta=.31 ; \mathrm{p}<.001)$, but not for informal governance $(B=.00 ; \mathrm{p}>.05)$. Hence, $\mathrm{H} 1$ is partially supported. $\mathrm{H} 2$ predicts a positive main effect of architectural knowledge on joint performance. We found a significant positive effect $(ß=.29 ; \mathrm{p}<.001)$, supporting H2. Although we did not hypothesize a main effect of the 
presence of the guardian vendor on joint performance, Model 2a showed a significant negative main effect $(ß=-.31 ; \mathrm{p}<.05)$.

Before adding the hypothesized interaction effects, we controlled for possible interactions of our hypothesized sources of IP capacity with modularity (in order to reflect IP requirements), and for the interaction of concentration with the choice of the guardian model. As the third column (Model 3a) shows, none of interactions of sources of IP capacity with modularity were significant. Conversely, we found a significant negative interaction effect of concentration with the choice of the guardian model $(ß=-.42 ; \mathrm{p}<.01)$.

The fourth column (Model 4a) presents the results of our full model, which includes the interaction effects hypothesized in $\mathrm{H} 3$ to $\mathrm{H} 5$. $\mathrm{H} 3$ predicts positive interaction effects of formal/informal inter-vendor governance and the client's architectural knowledge. As can be seen, only the interaction between informal inter-vendor governance and the client's architectural knowledge was significant and positive $(\beta=.13 ; \mathrm{p}<.05)$, thus partially supporting H3. Following the guardian-as-a-mediator perspective, H4 predicts negative interaction effects between the choice of the guardian model and the client's formal/informal inter-vendor governance (H4a), and with the client's architectural knowledge (H4b). As Model 4a shows, we found positive rather than negative interaction effects of the guardian model with formal $(\beta=.42 ; \mathrm{p}<.05)$ and informal $(\beta=.38 ; \mathrm{p}<.01)$ inter-vendor governance. $\mathrm{H} 4 \mathrm{a}$ is thus rejected. In line with $\mathrm{H} 4 \mathrm{~b}$, the interaction effects between the guardian model and architectural knowledge were significant $(\beta=-.52 ; \mathrm{p}<.01)$. While the results do not fully align with the predictions derived from the guardian-as-a-mediator perspective, they do align with the predictions derived from the guardian-as-an-architect perspective. In line with H5a, we found significant positive interaction effects of the guardian model with formal $(\beta=.42 ; \mathrm{p}<.05)$ 
and informal $(\beta=.38 ; \mathrm{p}<.01)$ inter-vendor governance. Moreover and in line with $\mathrm{H} 5 \mathrm{~b}$, we found significant negative interaction effects of the guardian model with architectural knowledge $(\beta=-.52 ; \mathrm{p}<.01)$.

Overall, our full model (Model 4a) showed the strongest explanatory power (adjusted $\mathrm{R}^{2}=.51$ ) of all the tested models (see the bottom of Table 6). The hypothesized interaction effects between sources of IP capacity (from Model 3 to Model 4) added statistically significant amounts of explained variance $\left(\Delta \mathrm{R}^{2}=.05 ; \Delta \mathrm{F}=3.63 ; \mathrm{p}<.01\right)$, supporting the relevancy of interaction effects expressed in $\mathrm{H} 3$ and $\mathrm{H} 5$.

To examine threats of endogeneity, alternative model specifications based on Heckman correction were undertaken and are reported in Table 7. Hypothesis testing based on these alternative models yielded coefficient signs and significance levels that were identical to those resulting from models $2 \mathrm{a}$ and $4 \mathrm{a}$. Moreover, the Inverse Mills Ratio was insignificant ( $p>.05)$ in all models. This suggests that the support found for our hypotheses is unlikely to be a statistical artefact of the potentially endogenous choice of the guardian model ${ }^{12}$.

\begin{tabular}{|l|r|r|r|}
\hline Table 7: Results of Alternative Models based on Heckman Correction \\
\hline \\
\hline Constant) & \multicolumn{1}{|c|}{ Model 2b } & \multicolumn{1}{|c|}{ Model 3b } & Model 4b \\
Concentration & $-.21(.23)$ & $-.12(.23)$ & $-.15(.22)$ \\
Modularity & $.03(.06)$ &. $\mathbf{1 5} *(.07)$ & $.17(.07)$ \\
Age of arrangement & $.22 * *(.06)$ & $.24 * *(.08)$ & $.24 * *(.08)$ \\
Client Size & $.02(.07)$ & $.04(.06)$ & $.02(.06)$ \\
Application Development & $-.06(.06)$ & $-.08(.06)$ & $-.05(.06)$ \\
Inverse Mills Ratio & $-.07(.16)$ & $-.06(.16)$ & $-.07(.15)$ \\
\hline
\end{tabular}

\footnotetext{
12 We performed two further analyses to examine threats of endogeneity. First, to examine whether clients deliberately chose highly capable vendors as their guardian vendors, we compared the clients' assessment of the vendors' individual (rather than joint) performance (measured through three items not used in this study, composite reliability .87). Individual performance was very similar for guardian vendors and for non-guardian vendors, with average standardized scores of -.02 for guardian vendors and .00 for non-guardian vendors (difference not statistically significant). This suggests that clients did not select highly capable vendors as their guardian vendors. Second, we estimated a switching regression model, using the movestay command in Stata [11]. The switching regression model produced results that were highly consistent with the results from OLS regression. Specifically, the differences between coefficients in sub-sample with guardian model and the coefficients in sub-sample with direct model were highly similar to interaction coefficients obtained from OLS regression (architectural knowledge: difference between coefficients in switching regression of -.55 compared to an OLS interaction effect of -.52 ; formal governance: difference between coefficients in switching regression of .37 compared to OLS interaction effect of .42; informal governance: difference between coefficients in switching regression of .35 versus OLS interaction effect .38).
} 


\begin{tabular}{|c|c|c|c|}
\hline Guardian & $-.20(.52)$ & $-.17(.17)$ & $-.14(.51)$ \\
\hline Formal governance & $.30 * * *(.07)$ & $.25 * * *(.07)$ & $.18 *(.08)$ \\
\hline Informal governance & $-.03(.07)$ & $.00(.07)$ & $-.08(.07)$ \\
\hline Architectural knowledge & $.27 * * *(.07)$ & $.33 * * *(.07)$ & $.46 * * *(.08)$ \\
\hline Modularity $\times$ Guardian & - & $-.00(.13)$ & $-.05(.14)$ \\
\hline Modularity $\times$ Formal governance & - & $-.12(.07)$ & $-.12(.07)$ \\
\hline Modularity $\times$ Informal governance & - & $.06(.05)$ & $-.02(.06)$ \\
\hline Modularity $\times$ Client's architectural knowledge & - & $.02(.07)$ & $.03(.07)$ \\
\hline Concentration $\times$ Guardian & - & $-.42 * *(.13)$ & $-.46 * * *(.13)$ \\
\hline Formal governance $\times$ Client's architectural knowledge & - & - & $-.01(.06)$ \\
\hline Informal governance $\times$ Client's architectural knowledge & - & - & $.13 *(.07)$ \\
\hline Guardian $\times$ Formal governance & - & - & $.42 *(.19)$ \\
\hline Guardian $\times$ Informal governance & - & - & $.37 * *(.14)$ \\
\hline Guardian $\times$ Client's architectural knowledge & - & - & $-.52 * *(.17)$ \\
\hline Adjusted $\mathrm{R}^{2}$ & .44 & .47 & .51 \\
\hline $\mathrm{R}^{2}$ & .49 & .54 & .59 \\
\hline
\end{tabular}

$(* \mathrm{p}<.05, * * \mathrm{p}<.01, * * * \mathrm{p}<.001$, results for dummy variables related to country and industry omitted $)$

\section{DISCUSSION}

The purpose of this study was to examine joint performance in multi-sourcing arrangements in light of the interdependencies between multiple vendors. Indeed, multi-sourcing has become a dominant sourcing model attracting growing attention in the IS community [6, 31, 49]. While multi-sourcing offers client firms numerous advantages through a competitive and yet cooperative regime, it also poses new challenges, mainly in the form of interdependencies that require the client firm to increase its efforts to achieve coordination and cooperation. Building on key IPV concepts, we framed these efforts as greater IP requirements. Given these IP requirements, a critical challenge in multi-sourcing arrangements is to generate sufficient IP capacity. In this regard, we proposed two possible sources of IP capacity. The first, the direct model (see Figure 1a), relies on internal sources of IP capacity only, seeking to leverage the client's formal and informal governance and architectural knowledge. The second, the guardian model (see Figure 1b), relies both on internal sources and on the use of a guardian vendor as a means of providing additional IP capacity. 


\section{Direct Model}

Our results regarding the direct model (i.e., the client alone managing the multisourcing arrangement) suggest that both formal inter-vendor governance and architectural knowledge lead to higher joint performance. In particular, each of these two sources of IP capacity (as captured in $\mathrm{H} 1$ and $\mathrm{H} 2$ ) individually equip the client firm with the IP capacity needed to manage interdependencies in the multi-sourcing arrangement. The results for the direct model highlight the importance of formal intervendor governance based on written procedures and the contractual agreement structure (e.g., objective and quantifiable measures) as a means of coping with coordination and integration efforts between vendors, manifested here as an IP challenge. Interestingly, formal inter-vendor governance seems to be an effective strategy irrespective of the client's level of architectural knowledge (see the insignificant interaction effect of formal inter-vendor governance and client's architectural knowledge).

On the other hand, informal inter-vendor governance seems to be effective only when the client has strong architectural knowledge (see the insignificant main effect of informal inter-vendor governance and the significant positive interaction effect of informal inter-vendor governance and client's architectural knowledge). The interaction plot depicted in Figure 3 below further illustrates the relationships. When a client possesses strong architectural knowledge (i.e., one standard deviation above the mean), greater informal inter-vendor governance is associated with higher joint performance. Conversely, when a client possesses weak architectural knowledge (i.e., one standard deviation below the mean), greater informal inter-vendor governance is associated with lower joint performance. The lack of a positive main effect of informal inter-vendor governance is rather surprising, given that the IS outsourcing literature has persistently found a positive effect of informal governance (often viewed as relational 
governance) on outsourcing performance in dyadic settings [e.g., 36]. One possible explanation for the surprising result in our study is that informal inter-vendor governance in triadic relationships is different from informal governance in dyadic relationships. Having more than two parties involved may erode the sense of being "informal" and make all parties involved feel part of a "formal" relationship. The sense of competition [49] between the vendors is also likely to contribute to such a "formal" attitude. The relational benefits seen in dyadic settings, therefore, may be less pronounced in multi-sourcing settings.

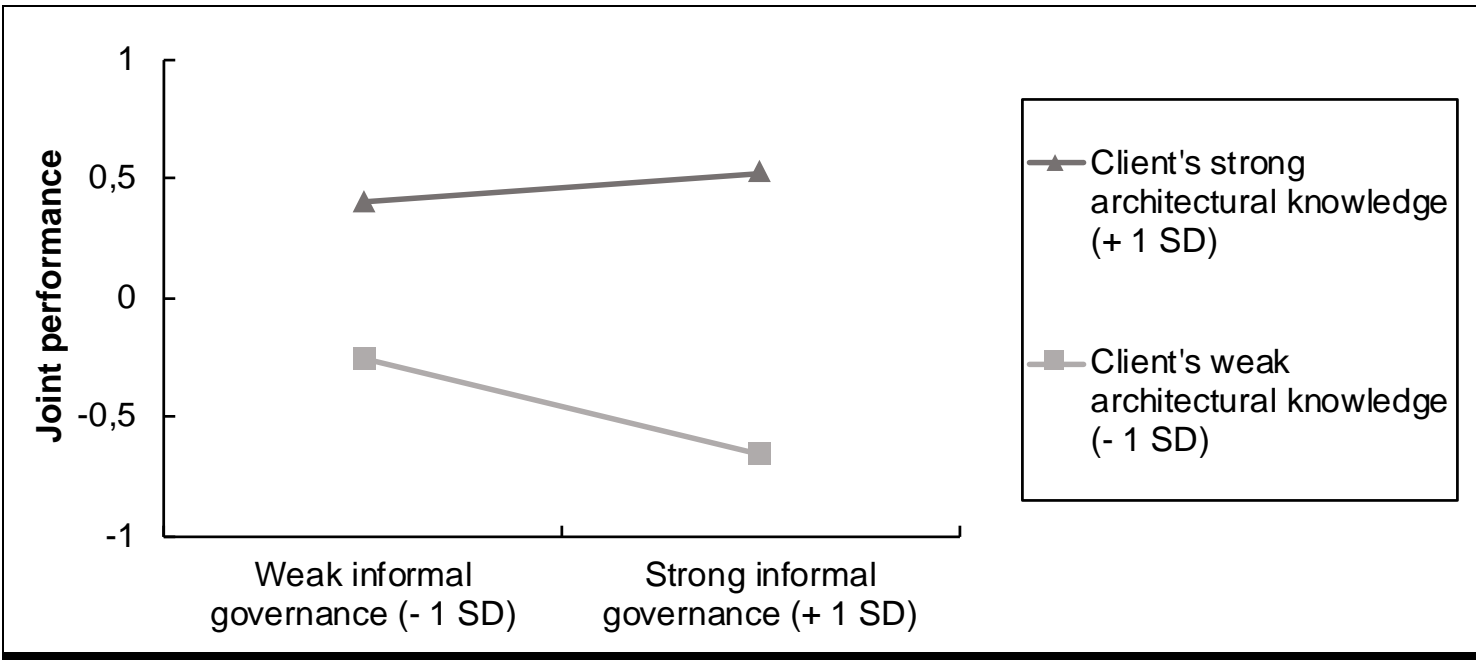

Figure 3: Informal governance affecting joint performance under strong versus weak client's architectural knowledge

\section{Guardian Model}

We found joint performance in arrangements using a guardian model to be very similar to arrangements using a direct model (4.06 versus 4.02 in a five-point scale, see the first row in Table 4). Nonetheless, we also found two significant interaction effects, suggesting that the effectiveness of the guardian model is contingent on the two internal sources of IP capacity.

Our results support the perspective that the guardian can best be utilized as an architect rather than as a mediator. Indeed, we found a complementary effect between the 
guardian vendor and the client's governance and a substitutive effect between the guardian vendor and the client's architectural knowledge, supporting our hypotheses derived from the guardian-as-an-architect perspective.

The interaction plot depicted in Figure 4 illustrates the complementary effect of the guardian model and inter-vendor governance. A guardian model is likely to diminish joint performance when the client firm exercises weak formal and informal inter-vendor governance (see Figure 4). Yet, the negative effect of the guardian model is reversed to positive when the client firm has strong formal and informal inter-vendor governance mechanisms in place. Therefore, in multi-sourcing settings, the internal IP capacity of governance (formal and informal) is required by the client in order to gain the benefits of the external IP capacity of architectural knowledge brought by the guardian vendor. This demonstrates the complementary effect of these two sources of IP capacity.

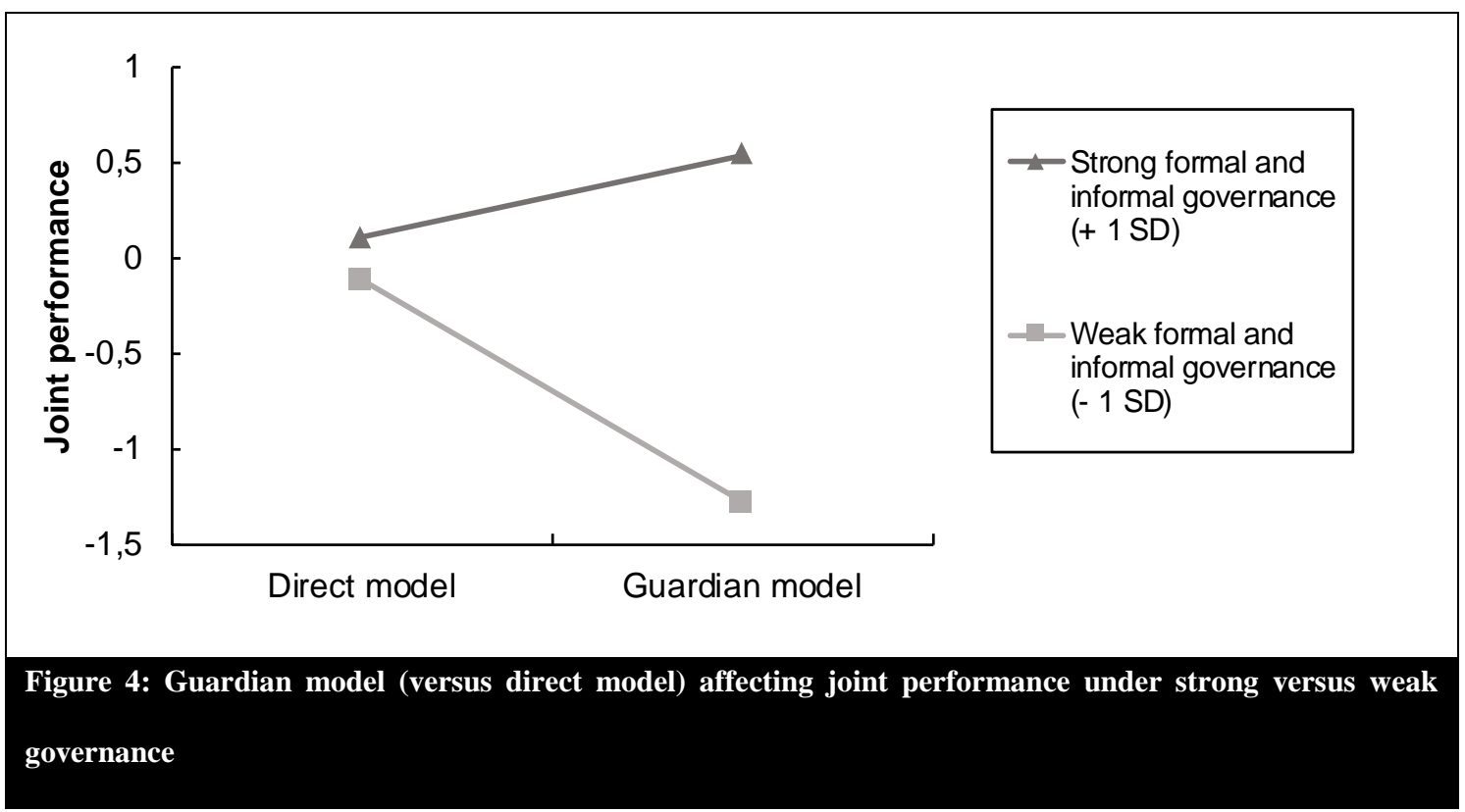

Our results also suggest a substitutive effect between the guardian's and the client's architectural knowledge, as illustrated by the interaction plot depicted in Figure 5. The guardian model improves joint performance when clients have weak architectural knowledge, while it worsens performance when clients have strong architectural 
knowledge. Indeed, these results suggest a substitutive effect between the IP capacity brought forward by the guardian vendor and the client's architectural knowledge. In this regard, the guardian model compensates for the client's weak in-house architectural knowledge and, therefore, a client with weak architectural knowledge may benefit from the guardian's ability to integrate interdependent sub-tasks in multi-sourcing arrangements. Conversely, clients who possess strong architectural knowledge may benefit to a much lesser extent from the guardian's integration ability.

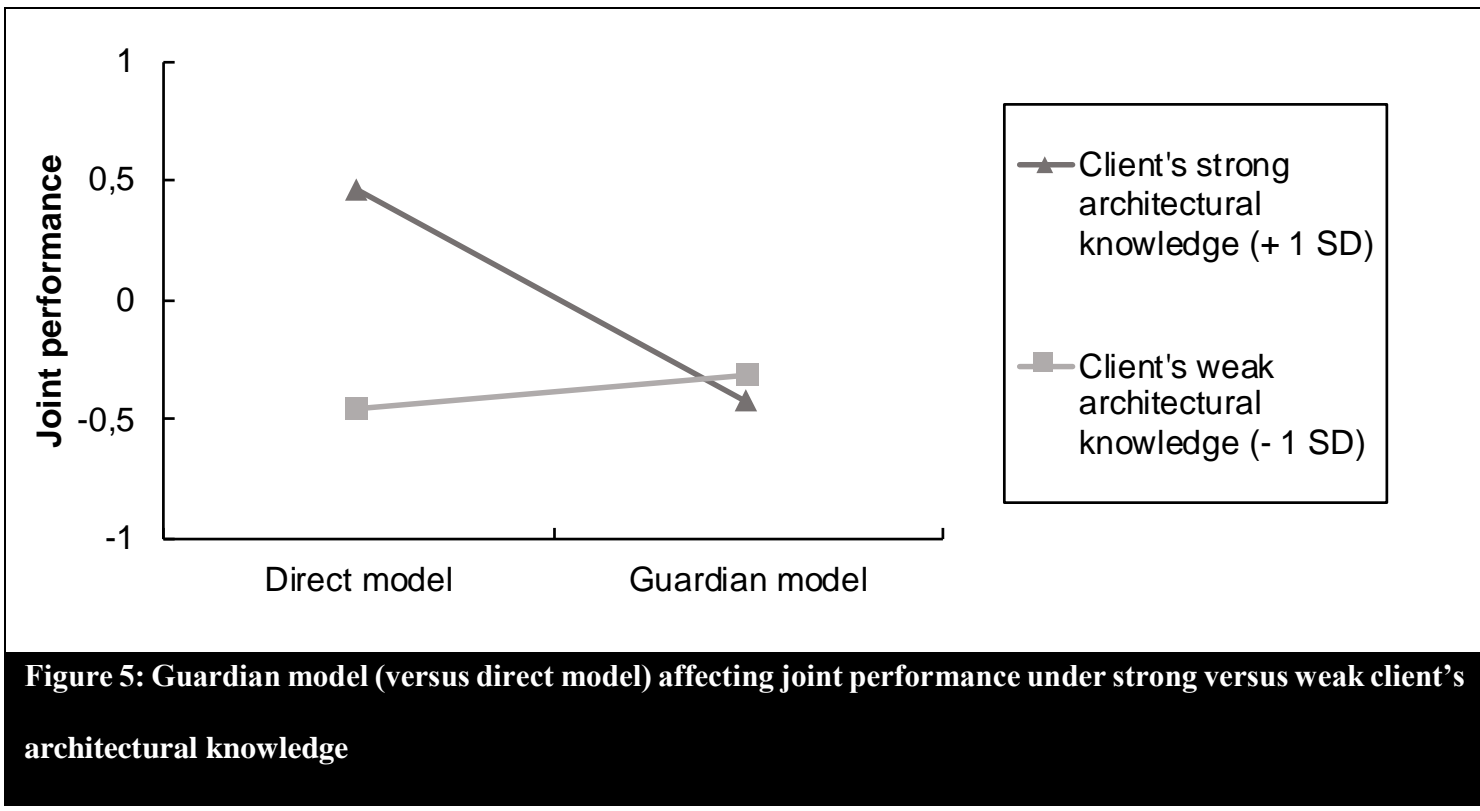

We found additional support for the perspective of 'guardian-as-an-architect. As depicted in Figure 6, the joint performance of the multi-sourcing arrangement will be higher should a client with weak architectural knowledge choose a guardian model and exercise strong formal and informal governance. On the other hand, a client with strong architectural knowledge will benefit from using the direct model, as Figure 7 depicts. Interestingly, both Figure 6 and 7 show that joint performance is at its lowest when the client chooses a guardian model and exercises weak inter-vendor governance. This is precisely the configuration prescribed by the guardian-as-a-mediator perspective. Irrespective of whether the client's architectural knowledge is high or low, employing 
a guardian-as-a-mediator model is likely to result in low levels of joint performance.

These findings bear important implications for theory and practice, on which we elaborate next.
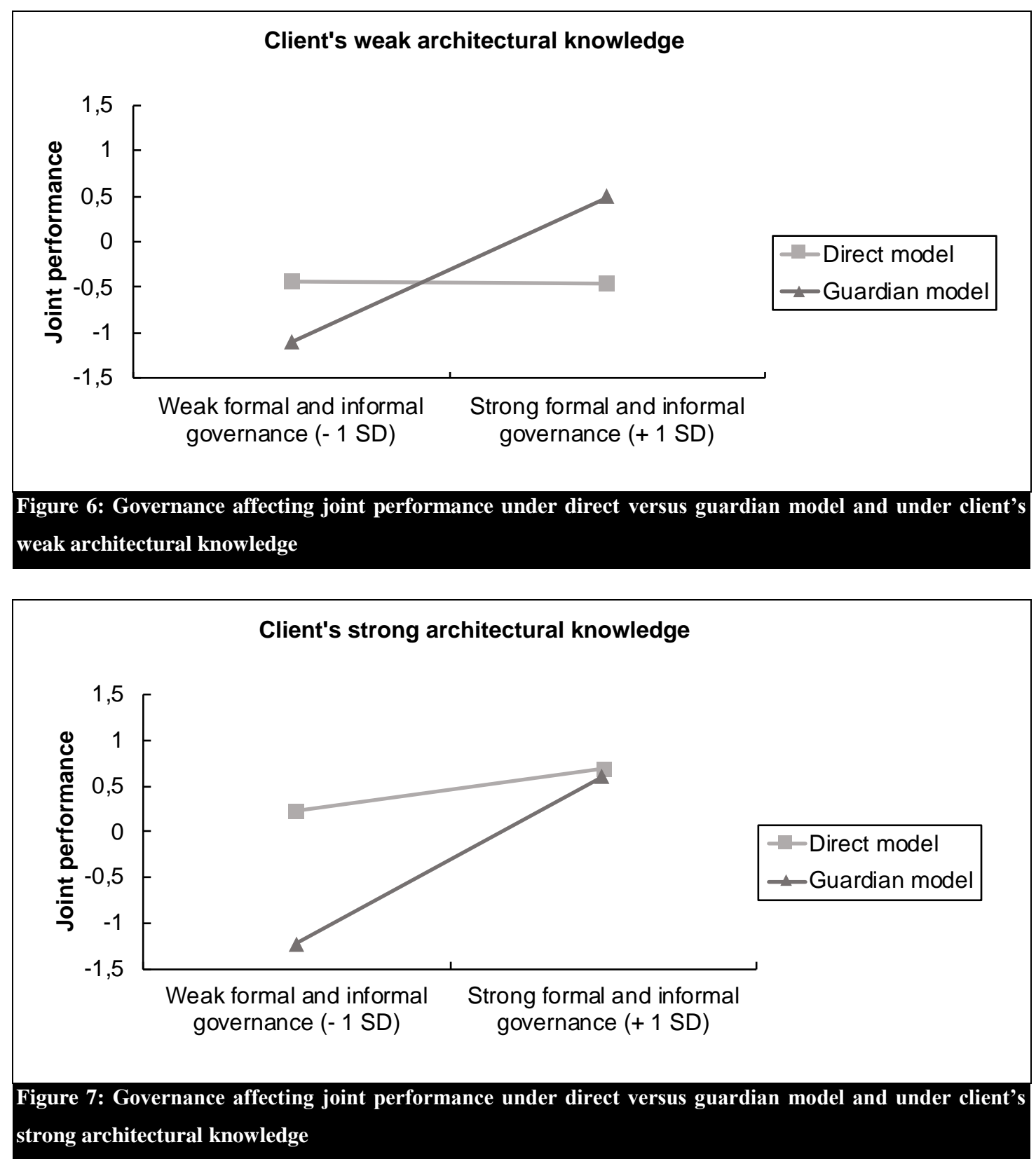

\section{IMPLICATIONS}

\section{Theoretical Contributions}

This paper offers two main contributions to the IS outsourcing literature. First, to our best knowledge, this is the first study to model and test determinants of joint 
performance in IS multi-sourcing arrangements. While the IS outsourcing literature has, by and large, examined dyadic relationships as a basis for understanding the determinants of outsourcing success [14], our study assumed interdependencies between multiple vendors, thus requiring an examination of triadic relationships at the minimum. As interdependencies may affect the likelihood of multi-sourcing success, formal and informal inter-vendor governance and architectural knowledge were examined as two key antecedents. Our study shows that while formal inter-vendor governance and the client's architectural knowledge are likely to improve multisourcing success, informal governance, often referred to as relational governance in the IS literature and considered key in achieving dyadic IS outsourcing success, shows no direct effect on joint performance. Our results show a positive effect of informal governance on joint performance only in conjunction with high levels of client's architectural knowledge, or with the choice of a guardian model. These results suggest that multi-sourcing does not simply mimic dyadic outsourcing at a larger scale. Its inherent independencies require unique governance mechanisms and associated abilities (i.e., architectural knowledge) directed towards the interface between vendors. The second contribution of this study is in offering insights into the role that a guardian vendor plays in a multi-sourcing arrangement. Bapna et al. [4] noted that, although the choice for or against a guardian model is one of the key design choices in multi-sourcing arrangements, "[t]here is little in the academic literature on the guardian vendor model" (p. 794). They called for research to examine "[w]hat aspects of the engagement should be handled by the guardian vendor and the client" (p. 794). Wiener and Saunders [49] argue that the guardian model can be regarded as a "mediated model", wherein the guardian vendor acts as a "single point of contact" (p. 213), mediating the interaction between the client and the remaining vendors. This would imply that the only actor 
responsible for governing interdependencies between vendors is the guardian vendor. Our results, however, show that it can be perilous for the client to withdraw from governance efforts and mandate these to the guardian vendor. In fact, the least successful multi-sourcing arrangements in our sample were those where the client appointed a guardian vendor and then exercised weak joint formal and informal governance (see Figure 6 and Figure 7). In other words, the clients who practiced the guardian-as-a-mediator model were the least successful. We therefore theorized an alternative role in which the guardian acts as an architect.

Our results do indeed suggest that a guardian vendor may be better understood as an architect than as a mediator. Much like the architect of a building contributes knowledge of how the elements of a building fit with each other, the guardian-as-anarchitect contributes knowledge as to how the sub-tasks of a multi-sourcing arrangement can be integrated. Two findings support the guardian-as-an-architect view. First, clients who lack architectural knowledge are particularly likely to benefit from the inclusion of a guardian vendor, suggesting that the guardian vendor compensates for the client's knowledge gaps. Second, just like the client's architectural knowledge enables more effective informal governance, so does utilizing the guardian vendor as an architect too. Informal inter-vendor governance involves complex ad hoc communication and decisions by the client, requiring considerable architectural knowledge in order to be exercised effectively. This knowledge may come either from the client, or from a guardian-as-an-architect to support the client in informal governance efforts. Thus, a guardian vendor complements the client's formal and informal inter-vendor governance while substituting the client's architectural knowledge. As such, the guardian model does not relieve clients from governance (as 
assumed in the guardian-as-mediator model), but it does help them compensate for knowledge gaps.

Another contribution of this study revolves around the body of research that explains the choice and effectiveness of governance mechanisms through an IPV lens. Indeed, the IPV-based literature stream on governance mostly argues that the choice of governance mechanisms determines the IP capacity of an organization, and that such IP capacity should fit IP requirements [2, 27, 32]. Although another literature stream implicitly argues that architectural knowledge is an important source of IP capacity in inter-organizational relationships $[7,24,38,43]$, these two literature streams have mostly developed in isolation. As a consequence, interactions between governance and knowledge have rarely been considered in IPV research. Conversely, a key argument of our study is that governance mechanisms, such as goal setting, planning, and direct interaction, enable effective IP to the extent that these mechanisms are enacted or assisted by a knowledgeable party.

\section{Practical Implications}

Our study offers specific recommendations for practice. Clients in multi-sourcing arrangements should consider their architectural knowledge when deciding for or against the guardian model. Clients with strong architectural knowledge (i.e., clients who understand well how the various sub-tasks outsourced to different vendors relate to each other) are advised to choose a direct model, whereas clients with weak architectural knowledge are better off with a guardian model. Although clients may believe that having a guardian model means they can economise on or relinquish governance efforts, this is not the case. Instead, clients are well advised to engage in extensive formal and informal governance efforts that involve all vendors. Specifically, clients should define and monitor the joint outcomes to be achieved and the joint 
procedures to be followed, and they should also put emphasis on informally interacting with all involved vendors at various levels. Importantly, extensive governance efforts are essential, both in a direct model, where the clients can leverage their own knowledge during informal governance in particular, and in a guardian model, where the guardian vendor should bring in additional knowledge to enable effective governance by the client.

\section{Limitations and Future Research}

There are several limitations to this study that may encourage future research. First, while this is one of the first studies to examine the effect of the guardian on a multisourcing arrangement, our study sheds little light on what exactly the guardian vendor does and what information capacities the guardian vendor brings to the multi-sourcing arrangement. Consequently, following on our guardian-as-an-architect perspective, our study provides a number of fruitful directions for future research. Future studies could take a practice-view and explicitly examine and document the IP requirements that multi-sourcing settings face. Consequently, future research could study the activities performed by the guardian vendor vis-à-vis the IP requirements, as well as in steering the relationships with the client and with other vendors in multi-sourcing arrangements. Building on this, future studies could also explore the relationship between the nature of the task (simple or complex) and the implications for the architectural knowledge and governance efforts that the guardian vendor contributes to multi-sourcing arrangements. Our study calls for a more in-depth examination of the practices and the knowledge contributions of the guardian vendor.

Second, while our measures of formal and informal inter-vendor governance were closely linked to the IPV, they did not include some mechanisms of contractual governance, such as contract duration and contract type. Future research could integrate 
these mechanisms into IPV conceptualizations. Moreover, although we focused on the client's inter-vendor governance (i.e., governance involving all vendors at the same time), we did not contrast inter-vendor governance efforts to governance efforts that involve only one vendor at a time (such as an SLA applicable for a single vendor only). We also see an opportunity for further research around the role of the client in a guardian vendor model. For example, drawing on our finding that informal governance - with the involvement of the client - complements the role of the guardian in achieving high levels of joint performance, a future study could zoom into such informal meetings and explore the activities performed by the client and the knowledge needed. Such a study could, in fact, explore the evolution of triadic relationships between client, guardian and other vendors and how their actions and knowledge evolve over time [8]. Ultimately, such zooming into the client and guardian vendor roles would also further address our call for a more in-depth understanding of the interactions between IP capacities, by studying interactions not only between capacities, e.g., informal and formal governance, but also between the underlying knowledge and the practices needed to bring such capacities to fruition.

\section{CONCLUSIONS}

The main objective in this paper was to examine joint-vendor performance in multisourcing. In particular, we took interest in understanding joint-vendor performance in two common multi-sourcing settings, namely, the direct model and the guardian model. Using the logic of the Information Processing View, we theoretically developed the idea that information processing capacity in multi-sourcing can be internal, i.e. the client's inter-vendor governance and the client's architectural knowledge, and external, i.e., the guardian vendor. To discover how these 3 sources of IP capacities affect jointvendor performance as well as interact with each other, we tested our model using an 
international data set of 189 IT multi-sourcing arrangements. We found that in the direct model, the client's formal inter-vendor governance and the client's architectural knowledge positively affect joint performance. We also found that a guardian vendor complements the client's formal and informal inter-vendor governance while substituting the client's architectural knowledge. These results suggest that the guardian's role is best understood as an architect, i.e. beneficial in terms of architectural knowledge, rather than as a mediator, i.e. beneficial in terms of inter-vendor governance. Put simply, client firms should consider using a guardian vendor to compensate for weak architectural knowledge while still maintaining strong formal and informal governance of all vendors.

\section{REFERENCES}

1. Agrawal, N., Smith, S.A., and Tsay, A.A., Multi-Vendor Sourcing in a Retail Supply Chain. Production and Operations Management, 11, 2 (2002), 157-182.

2. Andres, H.P. and Zmud, R.W., A Contingency Approach to Software Project Coordination. Journal of Management Information Systems, 18, 3 (2001/2002), 41-70.

3. Baldwin, C.Y. and Clark, K.B., The architecture of participation: Does code architecture mitigate free riding in the open source development model? Management Science, 52, 7 (2006), 1116-1127.

4. Bapna, R., Barua, A., Mani, D., and Mehra, A., Research Commentary: Cooperation, Coordination, and Governance in Multisourcing: An Agenda for Analytical and Empirical Research. Information Systems Research, 21, 4 (2010), 785-795.

5. Bensaou, M. and Venkatraman, N., Configurations of Interorganizational Relationships: A Comparison Between U.S. and Japanese Automakers Management Science, 41, 9 (1995), 1471-1492.

6. Bhattacharya, S., Gupta, A., and Hasija, S., Single-Sourcing Versus Multisourcing: The Roles of Output Verifiability on Task Modularity. MIS Quarterly, 42, 4 (2018), 1171-1186.

7. Brusoni, S., Prencipe, A., and Pavitt, K., Knowledge Specialization, Organizational Cloupling, and the Boundaries of the Firm: Why Do Firms Know More Than They Make? Administrative Science Quarterly, 46, 4 (2001), 597-621.

8. Cao, L., Mohan, K., Ramesh, B., and Sarkar, S., Evolution of Governance: Achieving Ambidexterity in IT Outsourcing. Journal of Management Information Systems, 30, 3 (2014), 115-140.

9. Chase, W.G. and Simon, H.A., Perception in Chess. Cognitive Psychology, 4, 1 (1973), 55-81.

10. Choi, T.Y. and Wu, Z., Taking the leap from dyads to triads: Buyer-supplier relationships in supply networks. Journal of Purchasing and Supply Management, 15, 4 (2009), 263-266.

11. Clougherty, J.A., Duso, T., and Muck, J., Correcting for self-selection based endogeneity in management research: Review, recommendations and simulations. Organizational Research Methods, 19, 2 (2016), 286-347. 
12. Cohen, L. and Young, A., Multisourcing: Moving beyond outsourcing to achieve growth and agility. (2006), Boston, MA: Harvard Business School Press.

13. Cohen, W. and Levinthal, D., Absorptive Capacity: A New Perspective on Learning and Innovation. Administrative Science Quarterly, 35, (1990), 128-152.

14. Dibbern, J., Goles, T., Hirschheim, R., and Jayatilaka, B., Information Systems Outsourcing: A Survey and Analysis of the Literature. DATA BASE, 35, 4 (2004), 6-102.

15. Galbraith, J.R., Organization Design. (1977), Reading, MA: Addison-Wesley.

16. Gefen, D. and Straub, D., A Practical Guide to Factorial Validity Using Pls-Graph: Tutorial and Annotated Example. Communications of the Association for Information Systems 16, 1 (2005), 91-109.

17. Goo, J., Huang, C.D., and Hart, P., A Path to Successful IT Outsourcing: Interaction Between Service-Level Agreements and Commitment. Decision Sciences, 39, 3 (2008), 469-506.

18. Goodhue, D., Lewis, W., and Thompson, R., Research Note-Statistical Power in Analyzing Interaction Effects: Questioning the Advantage of Pls with Product Indicators. Information Systems Research, 18, 2 (2007), 211-227.

19. Gopal, A. and Gosain, S., The Role of Organizational Controls and Boundary Spanning in Software Development Outsourcing: Implications for Project Performance. Information Systems Research, 21, 4 (2010), 960-982.

20. Gopal, A., Mukhopadhyay, T., and Krishnan, M., The Role of Software Processes and Communication in Offshore Software Development. Communications of the ACM, 45, 4 (2002), 193-200.

21. Grover, V., Cheon, M.J., and Teng, J.T.C., The Effect of Service Quality and Partnership on the Outsourcing of Information Systems Functions. Journal of Management Information Systems, 12, 4 (1996), 89-116.

22. Heckman, J., Sample Selection Bias as a Specification Error. Econometrica, 47, 1 (1979), 153-161.

23. Henderson, R.M. and Clark, K.B., Architectural Innovation: The Reconfiguration of Existing Product Technologies and the Failure of Established Firms. Administrative Science Quarterly, 35, 1 (1990), 9-30.

24. Hobday, M., Davies, A., and Prencipe, A., Systems integration: a core capability of the modern corporation. Industrial and Corporate Change, 14, 6 (2005), 11091143.

25. Huber, G.P., Organizational Learning: The Contributing Processes and the Literature. Organization Science, 2, 1 (1991), 88-115.

26. Huber, T.L., Ficher, T.A., Dibbern, J., and Hirschhem, R., A Process Model of Complementarity and Substitution of Contractual and Relational Governance in IS Outsourcing. Journal of Management Information Systems, 30, 3 (2013), 81-114.

27. Hui, P.P., Davis-Blake, A., and Broschak, J.P., Managing Interdependence: The Effects of Outsourcing Structure on the Performance of Complex Projects. Decision Sciences, 39, 1 (2008), 5-31.

28. Kirsch, L.J., Sambamurthy, V., Ko, D.G., and Purvis, R.L., Controlling Information Systems Development Projects: The View from the Client. Management Science, 48, 4 (2002), 484-498.

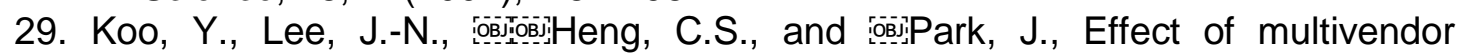
outsourcing on organizational learning: A social relation perspective. Information \& Management, 54, 3 (2017), 396-413.

30. Lee, J.N. and Kim, Y.G., Effect of partnership quality on IS outsourcing success: conceptual framework and empirical validation. Journal of Management Information Systems, 15, 4 (1999), 29-61.

31. Levina, N. and Su, N., Global Multisourcing Strategy: The Emergence of a Supplier Portfolio in Services Offshoring. Decision Sciences, 39, 3 (2008), 541-570. 
32. Mani, D., Barua, A., and Whinston, A., An Empirical Analysis of the of Information Capabilities Design on Business Process Outsourcing Performance. MIS Quarterly, 34, 1 (2010), 39-62.

33. Mani, D., Barua, A., and Whinston, A., An Empirical Analysis of the Contractual and Information Structures of Business Process Outsourcing Relationships. Information Systems Research, 23, 3 (2011), 618 - 634.

34. Oshri, I., Kotlarsky, J., and Willcocks, L.P., The Handbook of Global Outsourcing and Offshoring. 3rd edition ed. (2015), London: Macmillan.

35. Pinsonneault, A. and Kraemer, K.L., Survey research methodology in management information systems: An assessment. Journal of Management Information Systems, 10, 2 (1993), 75-105.

36. Poppo, L. and Zenger, T., Do formal contracts and relational governance function as substitutes or complements? Strategic Management Journal, 23, 8 (2002), 707-725.

37. Premkumar, G., Ramamurthy, K., and Saunders, C.S., Information Processing View of Organizations: An Exploratory Examination of Fit in the Context of Interorganizational Relationships. Journal of Management Information Systems, 22, 1 (2005), 257-294.

38. Prencipe, A., Corporate Strategy and Systems Integration Capabilities: Managing Networks in Complex Systems Industries, in The Business of Systems Integration, Prencipe, A., Davies, A., and Hobday, M., Editors. 2005, Oxford University Press: Oxford, UK. p. 114-132.

39. Sanchez, R. and Mahoney, J.T., Modularity, flexibility, and knowledge management in product and organization design. Strategic Management Journal, 17, Winter (1996), 77-91.

40. Schwarz, C., Toward an understanding of the nature and conceptualization of outsourcing success. Information \& Management, 51, 1 (2014), 152-164.

41. Siemsen, E., Roth, A., and Oliveira, P., Common Method Bias in Regression Models With Linear, Quadratic, and Interaction Effects. Organizational Research Methods, 13, 3 (2010).

42. Su, N. and Levina, N., Global Multisourcing Strategy: Integrating Learning From Manufacturing Into IT Service Outsourcing. IEEE Transactions on Engineering Management, 58, 4 (2011), 717-729.

43. Takeishi, A., Knowledge Partitioning in the Interfirm Division of Labor: The Case of Automotive Product Development. Organization Science, 13, 3 (2002), 321338.

44. Tanriverdi, H., Konana, P., and Ge, L., The choice of sourcing mechanisms for business processes. Information Systems Research, 18, 3 (2007), 280-299.

45. Tiwana, A., Does Technological Modularity Substitute for Control? A Study of Alliance Performance in Software Outsourcing. Strategic Management Journal, (2008).

46. Tiwana, A., Systems development ambidexterity: explaining the complementary and substitutive roles of formal and informal controls. Journal of Management Information Systems, 27, 2 (2010), 87-126.

47. Tiwana, A. and Keil, M., Control in Internal and Outsourced Software Projects. Journal of Management Information Systems, 26, 3 (2009), 9-44.

48. Tushman, M.L. and Nadler, D.A., Information Processing as an Integrating Concept in Organizational Design. Academy of Management Review, 3, 2 (1978), 613-624.

49. Wiener, M. and Saunders, C., Forced coopetition in IT multi-sourcing. Journal of Strategic Information Systems, 23, (2014), 210-225.

50. Wooldridge, J.M., Introductory Econometrics - a Modern Approach. 4th ed. (2009), Mason, $\mathrm{OH}$ : South-Western Cengage Learning. 